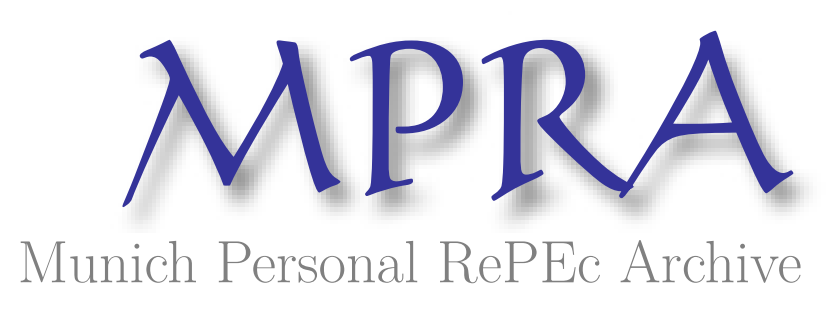

\title{
Droughts, Conflict, and the African Slave Trade
}

Boxell, Levi

Stanford University

12 October 2017

Online at https://mpra.ub.uni-muenchen.de/81924/

MPRA Paper No. 81924, posted 13 Oct 2017 09:17 UTC 


\title{
Droughts, Conflict, and the African Slave Trade*
}

\author{
Levi Boxell ${ }^{\dagger}$ \\ Stanford University
}

First Version: June 6, 2015

This Version: October 12, 2017

\begin{abstract}
Historians have frequently suggested that droughts helped facilitate the African slave trade. By introducing a previously unused dataset on 19th century rainfall levels in Africa, I provide the first empirical answer to this hypothesis. I show that negative rainfall shocks and long-run shifts in the mean level of rainfall increased the number of slaves exported from a given region and may have had a persistent impact on the level of development today. Using geocoded data on 19th century African conflicts, I show that these drought conditions also increased the likelihood of conflict, but only in the slave exporting regions of Africa. I also explore the role of household desperation, the internal African slave market, and disease outbreaks in explaining the negative relationship between droughts and slave exports. I find limited evidence for for these alternative mechanisms, with household desperation having the most empirical support. These results contribute to our understanding of the process of selection into the African slave trade.
\end{abstract}

JEL Classification: N37, N57, O15, Q54

Keywords: slave trade, conflict, climate, droughts

${ }^{*}$ Acknowledgments: I would like to thank Jiwon Choi, John T. Dalton, James Fenske, Matthew Gentzkow, Namrata Kala, Nathan Nunn, Craig Palsson, Andres Shahidinejad, Jesse M. Shapiro, Adam Storeygard, Michael Wong, and participants at the 2016 NEUDC for their comments and suggestions. I further thank James Fenske and Namrata Kala for their generous sharing of code and data. Funding was provided by the Stanford Institute for Economic Policy Research, the Institute for Humane Studies, and the National Science Foundation (grant number: DGE-1656518). Previously circulated as "A Drought-Induced African Slave Trade?".

${ }^{\dagger}$ Economics Department, Stanford University (Email: lboxell@stanford.edu) 


\section{Introduction}

The African slave trade significantly altered modern economic and cultural outcomes (Nunn, 2008). Areas that exported more slaves tend to be less trusting, display increased ethnic stratification, have lower literacy rates, and have an increased prevalence of polygyny (Nunn and Wantchekon, 2011; Whatley and Gillezeau, 2011; Obikili, 2015; Dalton and Leung, 2014). What caused certain regions to export more slaves than others? While the impact of the African slave trade is well documented, there have been less empirical investigations into the supply-side determinants of the slave trade. ${ }^{1}$

On the other hand, the historical literature is dense with speculation on what contributed to the rise of the slave trade in certain regions. One particular discourse surrounds the role of droughts. ${ }^{2}$ Historians suggest that Africa suffered a prolonged dry spell from 1630 to 1860, which helped facilitate the growing slave trade (Brooks, 2003, 102-3). In addition to attributing the growth of the slave trade to shifts in the mean level of rainfall, historians also attribute spatial and temporal variations in the slave trade to short-run fluctuations in rainfall. This connection is made in geographically dispersed areas — from Senegambia to Angola to Mozambique (Curtin, 1975; Miller, 1982; Newitt, 1995). Periods of drought are thought to have increased the number of slave exports due to increased conflict, people selling themselves into slavery, and migration that left populations vulnerable (Lovejoy, 2012, 29). However, not all historians follow this line of thought. Zeleza $(1997,34)$ calls these previous claims "an inept attempt to 'blame' the slave trade on nature and the victims themselves."

I introduce a previously unused dataset on 19th century rainfall levels in Africa (Nicholson, 2001) to provide a direct empirical answer to the debate on the role of droughts in the African slave trade. I find that negative rainfall shocks substantially increased the number of slaves exported from the region experiencing the shock. Specifically, a one standard deviation decrease in the previous year's rainfall is estimated to increase annual slave exports from a port by roughly 460 slaves. I also examine the role of temperature shocks and find a negative relationship between temperature shocks and slave exports, which corroborates the findings of Fenske and Kala (2015). In addition to rainfall shocks, long-run trends in the mean rainfall level also display a negative relationship with the number of slaves ex-

\footnotetext{
${ }^{1}$ Nunn and Puga (2012), Fenske and Kala (2015), and Whatley (Forthcoming) are exceptions.

${ }^{2} \mathrm{An}$ in-depth review of the historical context of slavery in pre-colonial Africa is beyond the scope of this paper and can be found elsewhere (Lovejoy, 2012; Nunn, 2008).
} 
ported from a port. Furthermore, I show how rainfall-induced changes in the number of slave exports can have long-run impacts on the level of development today. Areas that were abnormally dry during periods of high slave exports have lower levels of average night-time light intensity.

I explore the role of four different mechanisms in explaining the relationship between droughts and slave exports: conflict, household desperation, the internal demand for slaves in Africa, and disease outbreaks. Historical anecdotes suggest that long-run precipitation trends during the slave trade pushed certain groups, such as the Imbangala in Angola, to shift labor allocation between conflict (i.e., the slave trade) and agriculture (Miller, 1982). In general, it is suggested that conflict was the largest producer of slaves during the transAtlantic slave trade (Lovejoy, 2012, 85). I use geocoded data on interethnic group conflict in Africa (Brecke, 1999) to show that droughts increased the likelihood of interethnic group conflict in Africa, but only in the slave exporting regions. Consistent with Iyigun, Nunn and Qian (2017) who find a negative relationship between temperature and conflict during the Little Ice Age in the Northern Hemisphere, negative temperature shocks also increase conflict prevalence in early 19th century Africa, which was experiencing abnormally cool weather overall during this time period. These results provides strong support for conflict being a primary mechanism through which climate conditions impacted slave exports. The fact that the climate-conflict relationship is strongest in the slave exporting regions of Africa suggests that the slave trade may have exacerbated the climate-conflict relationship in Africa by altering the incentives for interethnic group conflict.

Numerous Angolan anecdotes also relate short-run precipitation shocks to desperate consumption smoothing strategies that include selling family members, commonly children, into slavery at substantially reduced prices (Dias, 1981). Children were also frequently used as 'pawns,' or debt collateral, in West Africa. When loans were defaulted on, the pawns would be sold into slavery (Sparks, 2014, 138). To examine the potential role of this mechanism, I use microdata on the age of illegally exported slaves whose ships had been captured by the British after the 1807 Slave Trade Act. I find that droughts increased the proportion of slave exports that are children.

Keeping slaves domestically was also common practice in Africa. While males were typically exported, females were typically kept for the internal slave market in Africa (Geggus, 1989). In fact, some have suggested that higher levels of female slave exports may be indica- 
tive of internal economic hardships (Klein, 1997, 36). Using the same microdata from ships captured by the British, I find no strong evidence that drought conditions are positively correlated with female slave exports.

Finally, I examine the potential role for disease epidemics to explain the relationship. Historical anecdotes suggest that Africans primarily suffered from European diseases during drought conditions and that, in response, slave traders would try to sell off their accumulated holdings quickly to avoid suffering a financial loss from increased mortality (Miller, 1982). If this inventory response to disease outbreaks is playing a major role in the relationship between droughts and slave exports, trans-Atlantic slave mortality should increase during drought conditions due to the disease burden. Instead, the mortality rate on slave ships is lower during droughts.

Overall, I find that conflict and household desperation are the two mechanisms with the greatest support empirically for explaining the relationship between droughts, or climate conditions more broadly, and slave exports. This corroborates the historical literature where these two mechanisms are emphasized. On the other hand, I find little to no support for the internal market for slaves and disease outbreak mechanisms, which, though mentioned in the historical literature, are not as prominent.

\subsection{Related Literature}

The trans-Atlantic slave trade was a collaborative effort between the Americas, Europe, and Africa. On the European-side, previous work examines the importance of managerial ability, market distortions, and the 1807 British Slave Trade Act in contributing to the temporal and spatial variation in slave exports (Dalton and Leung, 2015a,b; Lovejoy and Richardson, 1995). On the African-side, studies emphasize geography, the gun-slave cycle, and temperature as determinants of the level of slave exports from a given region (Nunn and Puga, 2012; Whatley, Forthcoming; Fenske and Kala, 2015). I show the importance of droughts in explaining the degree to which a region participated in the slave trade. I also corroborate the previous findings of a negative relationship between temperature and slave exports by demonstrating its robustness to conditioning on rainfall, though with varied significance and some sensitivity across specifications. Furthermore, I provide detailed empirical and anecdotal evidence for the specific mechanisms through which these marginal slaves were acquired which gives a more complete picture of the slave trade market within Africa. 
There is also a growing set of work on the relationship between climate conditions and conflict. Most contemporary studies show that both higher temperatures and extreme deviations (positive or negative) in rainfall increase conflict (see Hsiang, Burke and Miguel (2013) for a recent review of the climate-conflict literature). On the other hand, Iyigun, Nunn and Qian (2017) show that temperature is negatively correlated with conflict during the 'Little Ice Age' (1400-1900) in Europe, North Africa, and the Near East and argue that this can be attributed to temperatures below the optimal bandwidth for agricultural production. In addition, it has been suggested that Africa may have also experienced cooling during the Little Ice Age (Nicholson et al., 2013). Consistent with Iyigun, Nunn and Qian (2017), I show that slave exporting ports in Africa were abnormally cool during the early 19th century, and as a result, higher temperatures decreased conflict prevalence (with some sensitivity to specification) in the surrounding regions. At the same time, I find that droughts (and flooding) increased conflict prevalence. Furthermore, I find that the relationship between climate conditions and conflict is strongest in the slave exporting regions of Africa. This is consistent with findings by Fenske and Kala (2017) that the suppression of the slave trade in 1807 by the British in West Africa increased the incentives for conflict in the slave exporting regions of West, West-Central, and East Africa. These facts suggest that societies in Africa adjusted their allocation of labor between agriculture and conflict in response to changes in the opportunity costs induced by climate conditions and that the slave trade may have exacerbated this relationship.

Other work examines behavioral changes by poor households in response to income shocks (Morduch, 1995; Jappelli and Pistaferri, 2010). Low-income societies often lack formal credit markets to smooth consumption patterns. This leads to the use of informal consumption smoothing strategies. One strategy available is shifting labor allocation. For example, farmers in developing countries smooth consumption by increasing non-agricultural labor allocation in response to lower commodity prices (Adhvaryu, Kala and Nyshadham, 2015). Another consumption smoothing strategy is the sale and manipulation of human assets. There has been a growing literature on the use of marriage as a consumption smoothing strategy in cultures where bride prices are prominent (Hoogeveen, Klaauw and Lomwel, 2011; Corno and Voena, 2015). In cultures with dowries, violence against women tends to increase during adverse weather shocks in an attempt to extract further dowry payments (Sekhri and Storeygard, 2014). Women in low income societies also tend to migrate to different 
regions for marital purposes. This migration effectively operates as family insurance against region-specific weather shocks (Rosenzweig and Stark, 1989). I contribute to this literature by demonstrating how historical African societies sold household members and shifted labor allocations towards the slave trade in response to negative income shocks.

The rest of the paper is outlined as follows. Section 2 explains the data, Section 3 gives the main empirical results, Section 4 examines the potential mechanisms within the historical context of the slave trade, and Section 5 concludes.

\section{Data}

\section{$2.1 \quad$ Rainfall}

The dataset on rainfall anomalies comes from Nicholson (2001) and is stored at the National Oceanic and Atmospheric Administration's World Data Center for Paleoclimatology. ${ }^{3}$ This dataset is previously unused in the economic literature, but provides a valuable resource for understanding how the climate impacted pre-colonial and colonial Africa. To construct the historical values, the continent is first partitioned into homogeneous rainfall regions, which were introduced by Nicholson (1986) and can be seen in Figure 1. The regions are constructed using spatial and temporal variations in rainfall from 1901 to 1973. Areas with highly correlated temporal variation in rainfall are denoted homogeneous regions.

The key idea from these homogeneous regions is that information about rainfall from any point within the region can be used to describe rainfall across the entire region with a relatively high degree of accuracy. This allows for the reconstruction of historical rainfall values for each year from 1801 to 1900 . The data is reconstructed using a combination of rain gauge data, written historical descriptions, ${ }^{4}$ and spatial interpolation/imputation. ${ }^{5}$ The use of non-gauge primary sources prevents the measurement of rainfall in inches or centimeters per year. Therefore, Nicholson (2001) uses a seven-tier rating system that describes the amount of rainfall in a given year. Table 1 gives the different levels and their description.

\footnotetext{
${ }^{3}$ The data can be found at https://www.ncdc.noaa.gov/paleo-search/study/12201 as of October 12, 2017.

${ }^{4}$ These include the writings of explorers, settlers and missionaries, local oral and written tradition, and hydrological records of lakes and rivers.

${ }^{5}$ Missing values are imputed using spatial imputation from nearby regions or a principal component technique.
} 
I then assign each port the rainfall value for the region in which it is located after subtracting the region's mean rainfall level between 1801 and $1866 .{ }^{6}$ Figure A1 plots the rainfall level for each rainfall region over the time period.

\subsection{Temperature}

For temperature data, I utilize a dataset constructed in a manner similar to the rainfall dataset. Using a wide variety of proxy and instrumental climate indicators and calibrating the model on known data, Mann, Bradley and Hughes (1998) develop a $5^{\circ} \times 5^{\circ}$ global grid of temperature anomalies. I follow Fenske and Kala (2015) by using a bilinear interpolation of the four nearest temperature points for each port. ${ }^{7}$ As done for the rainfall variable, I also take the difference between a given year's temperature value and the mean temperature value for each port between 1801 and 1866. Figure A2 plots the temperature variable for each rainfall region over the time period (see online appendix for details on this construction).

Figure A3 (taken from Mann et al. (2009)) shows the average temperature anomaly across the globe from 1600-1850 and corroborates the claim that Africa experienced an overall cooling during the Little Ice Age, particularly in the coastal regions of West-Central Africa. Figure A4 shows that this is abnormally cool weather was even more prominent for the ports that exported the most slaves and was at a level near that experienced by the Northern Hemisphere in general during the Little Ice Age (Mann et al., 2009).

\subsection{Slave Exports}

The data on slave exports originally come from Eltis et al. (1999). Slaves exported from a known port are assigned to that port. Slaves exported from a known area, but unknown port, are assigned proportionally to the ports in the area based upon the known exports in the same year. Slaves exported from an unknown area and unknown port are assigned proportionally to all ports based upon the known exports for that year. ${ }^{8}$ I then restrict my

\footnotetext{
${ }^{6}$ Empirically, this demeaning makes little to no difference when port fixed effects are included. However, it allows the descriptive statistics to give a truer picture of the underlying variation and helps account for any systematic differences in the historical reconstruction across regions when port fixed effects are excluded.

${ }^{7}$ I use the data provided in this format from Fenske and Kala (2015). More detailed explanations of the data construction can be found within Fenske and Kala (2015).

${ }^{8} \mathrm{I}$ utilize the data set of this format from Fenske and Kala (2015).
} 
Figure 1: Homogeneous Rainfall Zones, Temperature Points, and Ports

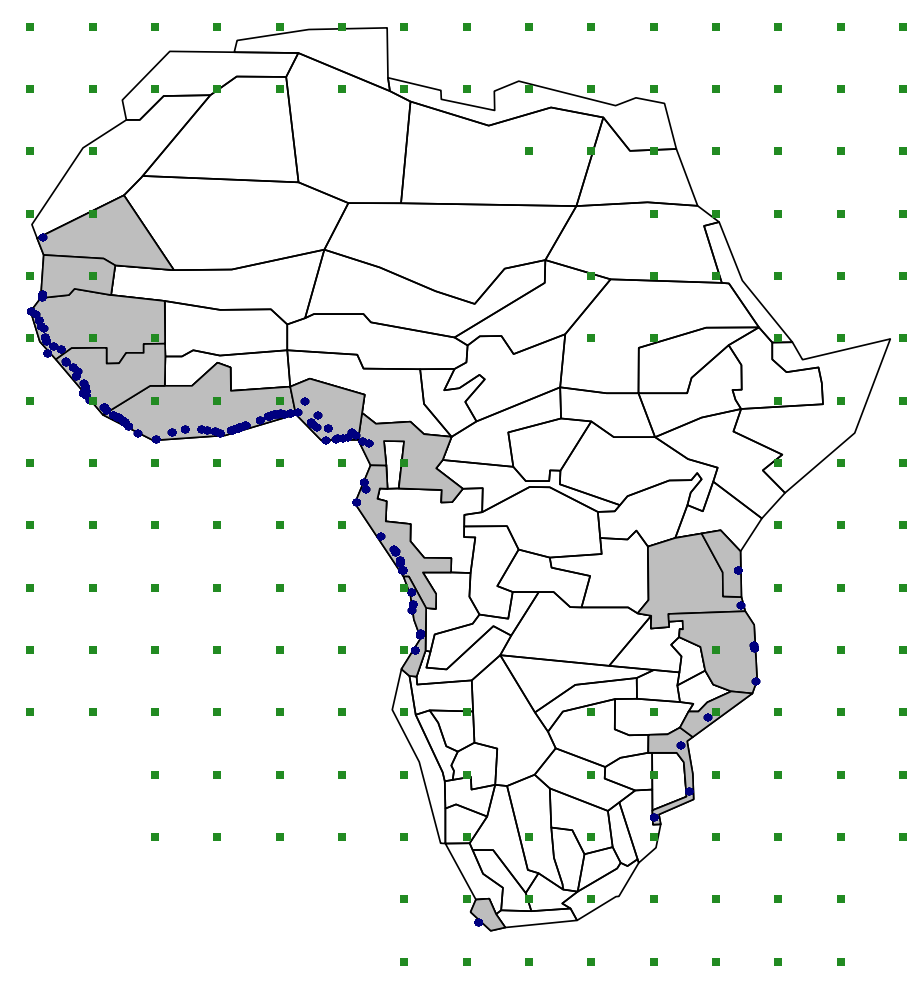

Notes: The grey regions are the homogeneous rainfall regions used in the study taken from Nicholson (2001). The blue dots are the port locations taken from Fenske and Kala (2015). The green squares are the temperature points taken from Mann, Bradley and Hughes (1998).

sample to those ports covered by a rainfall region. ${ }^{9}$ This gives 123 ports.

The average slave exporting port in the sample exported roughly 410 slaves annually, as shown in Table A1. To give a rough sense of the the temporal dynamics of slave exports for this time period, I plot the total slave exports from each rainfall region in Figure A5. This time period contains roughly 25 percent of the estimated 12 million slaves exported from Africa between 1501 and 1866. Figure A6 shows the annual level of slave exports across all ports in the sample. Figure A7 shows the annual level of slave exports in the sample separately for West Africa, West-Central Africa, and East Africa as defined by Figure A8.

\footnotetext{
${ }^{9}$ I include ports that are roughly within $30 \mathrm{~km}$ of the geo-referenced rainfall region map and assign them the rainfall value of the nearest rainfall region. The closest port excluded is "Fernando Po" or present-day Malabo. See the online appendix for more details on the port sample.
} 


\section{Empirical Model and Results}

The main empirical model is

$$
\operatorname{Slaves}_{i t}=\max \left(0, \delta_{i}+\eta_{t}+\operatorname{Rain}_{i,(t-1)} \beta+\operatorname{Temp}_{i t} \gamma+\epsilon_{i t}\right)
$$

where Slaves $_{i t}$ denotes the amount of slaves exported from port $i$ at time $t, \operatorname{Rain}_{i(t-1)}$ is a representation of the previous year's rainfall, Temp $_{i t}$ denotes the contemporary temperature anomaly, $\delta_{i}$ is a port-specific fixed effect, and $\eta_{t}$ is a year-specific fixed effect. ${ }^{10}$ Since Slaves $_{i t}$ is constrained to be non-negative, Slaves $_{i t}=0$ represents a corner solution. Typical OLS regressions are inconsistent under these assumptions (Wooldridge, 2002, 524-5). This leads to the use of a type-I Tobit model. The main parameters of interest are $\beta$ and $\gamma$ whose identification comes from the exogenous variation in rainfall and temperature shocks across regions after controlling for unobserved port-specific heterogeneity and temporal changes in the slave trade. This specification and many of the remaining specifications in this section build on Fenske and Kala (2015). The similarity in specifications allows for a better understanding of any discrepancies in the estimated impact of temperature.

Out of concern for non-linearity, I initially model the impact of rainfall on slave exports by creating an indicator variable for each of the seven rainfall levels. Table 1 shows that the impact of rainfall on slave exports is approximately linear with the only significant anomaly being the rainfall level that typically corresponds with flooding conditions. This result motivates the use of a single variable denoting the port-demeaned rainfall level along with a flood indicator variable, which takes on the value of one when the port-demeaned rainfall level is greater than three.

Using this specification, my main result in Column (1) of Table 2 shows that the coefficient on rainfall is negative and significant at the one percent level. Specifically, a one level (standard deviation) decrease in a port's rainfall in the previous year is estimated to cause approximately 290 (460) more slaves to be exported from the port. This result confirms the hypothesis proposed by various historians of the trans-Atlantic slave trade that droughts increased slave exports (Curtin, 1975; Newitt, 1995; Brooks, 2003; Lovejoy, 2012). When controlling for temperature shocks, the coefficient on rainfall is relatively unchanged as shown

\footnotetext{
${ }^{10}$ The temporally lagged rainfall shock may appear arbitrary. However, I explore various lags in Figure A9. The temporal lag on rainfall is also consistent with the temporal lag found by Crost et al. (2015) for the impact of rainfall on civil conflict when operating through agricultural production.
} 
Table 1: Non-linearity of Rainfall?

\begin{tabular}{|c|c|c|c|}
\hline \multirow[b]{2}{*}{ Variable } & \multirow[b]{2}{*}{ Description } & \multicolumn{2}{|c|}{ Slave Exports } \\
\hline & & Coefficient & SE \\
\hline \multicolumn{4}{|c|}{ Rain Level $t_{t-1}$} \\
\hline-3 & Severe drought; Causes famine and/or migration & 415.3 & $(422.6)$ \\
\hline-2 & Drought & -120.3 & $(318.3)$ \\
\hline-1 & Dry & -298.5 & $(414.8)$ \\
\hline 0 & Average & 0 & - \\
\hline 1 & Wet & -615.6 & $(484.9)$ \\
\hline 2 & Anomalously wet & -1960.0 & $(507.9)$ \\
\hline 3 & Severe Rainfall; Typically causes flooding & -606.6 & $(470.4)$ \\
\hline $\operatorname{Temp}_{t}$ & & -1911.9 & $(1456.7)$ \\
\hline Obs. & & 7995 & \\
\hline
\end{tabular}

Notes: Tobit regression with port and year fixed effects. Dependent variable is the number of slaves exported from a port in a given year. Standard errors are clustered by rainfall region.

in Column (3) of Table 2. The negative coefficient on temperature shocks corroborates the findings of Fenske and Kala (2015) and suggests that their main result is robust, at least in sign, to the inclusion of rainfall shocks, though it is not significant at conventional levels.

The impact of climate conditions on slave exports is not limited to shocks, but long-run trends or climate change could also impact the level of slave exports. To examine the impact of climate changes, I let Rain Trend ${ }_{t}\left(\right.$ Temp Trend $\left.{ }_{t}\right)$ denote the lagged moving average of $\operatorname{Rain}_{t}\left(\mathrm{Temp}_{t}\right)$ and let Rain Shock ${ }_{t-1}\left(\right.$ Temp Shock $\left.{ }_{t}\right)$ denote the previous (contemporary) year's deviation from Rain $\operatorname{Trend}_{t}\left(\right.$ Temp Trend $\left._{t}\right)$. I use moving averages of length 5, 10, and 20 years.

As reported in Table 3, the coefficients on Rain Trend ${ }_{t}$ and Rain Shock ${ }_{t-1}$ are both negative for all moving averages, though with varying statistical significance. Using the standard deviations reported in Table A1, we see that a one standard deviation change in Rain Trend ${ }_{t}$ has a substantially larger impact than a one standard deviation change in Rain Shock $k_{t-1}$ for the 5-year and 10-year moving averages, but they are approximately equal for the 20-year moving average. This suggests that, while rainfall realizations from the past 5 to 10 years are important for determining slave exports, realizations from more than 10 years ago primarily dilute the information contained within the trend variable and thus, increase the relative importance of the signal contained in the shock variable. 
Table 2: Main Results

\begin{tabular}{|c|c|c|c|c|c|}
\hline \multicolumn{5}{|c|}{ Slave Exports } & \multirow{2}{*}{$\begin{array}{c}\log (\text { Light Intensity) } \\
(4)\end{array}$} \\
\hline & (1) & $(2)$ & (3) & & \\
\hline $\operatorname{Rain}_{t-1}$ & $\begin{array}{l}-288.2 \\
(85.1)\end{array}$ & & $\begin{array}{l}-280.3 \\
(78.5)\end{array}$ & Weighted Rain & $\begin{array}{l}-0.100 \\
(0.061)\end{array}$ \\
\hline Flood $_{t-1}$ & $\begin{array}{l}1218.5 \\
(639.9)\end{array}$ & & $\begin{array}{l}1158.8 \\
(640.9)\end{array}$ & Weighted Flood & $\begin{array}{l}-0.134 \\
(0.067)\end{array}$ \\
\hline Temp $_{t}$ & & $\begin{array}{c}-1608.1 \\
(1637.6)\end{array}$ & $\begin{array}{l}-1394.6 \\
(1509.3)\end{array}$ & Weighted Temp & $\begin{array}{l}-0.634 \\
(0.301)\end{array}$ \\
\hline Port F.E. & Yes & Yes & Yes & Controls & Yes \\
\hline Year F.E. & Yes & Yes & Yes & & \\
\hline Obs. & 7995 & 8118 & 7995 & Obs. & 123 \\
\hline
\end{tabular}

Notes: Columns (1) - (3) use Tobit regressions with standard errors clustered by rainfall region in parentheses. Dependent variable is the number of slaves exported from a port in a given year. Column (4) uses OLS with standard errors clustered by rainfall region in parentheses. Dependent variable is the $\log$ of average nighttime light intensity within $500 \mathrm{~km}$ of the port in 2009 . Control variables include malaria suitability, presence of petroleum, distance to nearest foreign port, number of raster light intensity points within $500 \mathrm{~km}$, AEZ zone, absolute latitude, longitude, average 1902-1980 temperature, average deviation from 1902-1980 temperature across 1801-1866, average demeaned rainfall level across 1801-1866, and average flood indicator across 1801-1866.

The coefficients on Temp Shock $k_{t}$ and Temp Trend ${ }_{t}$ are also negative when examined together for all moving averages, though Temp Trend $_{t}$ is statistically insignificant throughout and even positive when excluding Temp Shock ${ }_{t}$. Furthermore, we see that the relative impact of a one standard deviation change is much larger for Temp Shock ${ }_{t}$ and, while imprecisely estimated, the magnitude of a one standard deviation change in Temp Trend ${ }_{t}$ is close to zero.

I also examine the persistent impact of climate anomalies during the 19th century slave trade on modern outcomes using port-level night-time light data as a proxy for development. Each port is assigned the average light intensity for the area within $500 \mathrm{~km}$ of the port in $2009 .{ }^{11}$ I use a weighted sum of the anomalies for each port, $i$, in the following fashion:

$$
\text { Weighted Rain }{ }_{i}=\sum_{t} \frac{\text { Slaves }_{t} \times \text { Rain }_{i(t-1)}}{\sum_{t} \text { Slaves }_{t}}
$$

\footnotetext{
${ }^{11}$ I use the data provided by Fenske and Kala (2015).
} 
Table 3: Trends and Shocks

\begin{tabular}{|c|c|c|c|c|c|c|}
\hline & & pendent I & able: Sla & Exports & & \\
\hline & 5 Yea & MA & $10 \mathrm{Yt}$ & r MA & $20 \mathrm{Ye}$ & r MA \\
\hline & (1) & (2) & (3) & (4) & (5) & (6) \\
\hline Rain $\operatorname{Trend}_{t}$ & $\begin{array}{c}-461.6 \\
(188.3)\end{array}$ & $\begin{array}{l}-473.5 \\
(191.5)\end{array}$ & $\begin{array}{l}-746.9 \\
(311.6)\end{array}$ & $\begin{array}{l}-724.3 \\
(319.3)\end{array}$ & $\begin{array}{c}-826.0 \\
(688.1)\end{array}$ & $\begin{array}{c}-800.3 \\
(649.2)\end{array}$ \\
\hline Rain Shock $_{t-1}$ & & $\begin{array}{l}-90.6 \\
(50.4)\end{array}$ & & $\begin{array}{c}-99.5 \\
(87.7)\end{array}$ & & $\begin{array}{r}-227.7 \\
(98.2)\end{array}$ \\
\hline Temp Trend ${ }_{t}$ & $\begin{array}{c}-484.9 \\
(1718.0)\end{array}$ & $\begin{array}{l}-2375.9 \\
(1998.6)\end{array}$ & $\begin{array}{l}1758.7 \\
(3487.4)\end{array}$ & $\begin{array}{l}-768.0 \\
(2876.4)\end{array}$ & $\begin{array}{c}5956.3 \\
(12882.5)\end{array}$ & $\begin{array}{c}-592.4 \\
(11002.3)\end{array}$ \\
\hline Temp Shock $_{t}$ & & $\begin{array}{c}-2420.4 \\
(1546.0)\end{array}$ & & $\begin{array}{c}-2494.8 \\
(1505.5)\end{array}$ & & $\begin{array}{c}-3371.3 \\
(2091.9)\end{array}$ \\
\hline Port F.E. & Yes & Yes & Yes & Yes & Yes & Yes \\
\hline Year F.E. & Yes & Yes & Yes & Yes & Yes & Yes \\
\hline Obs. & 7503 & 7380 & 6888 & 6765 & 5658 & 5535 \\
\hline
\end{tabular}

Notes: Tobit regressions with port and year fixed effects and standard errors clustered by rainfall region in parentheses. Unless otherwise specified, the dependent variable is the number of slaves exported from a port in a given year. 'Rain Trend ${ }_{t}$ ' is a moving average of the previous rainfall levels. 'Rain Shock $\mathrm{k}_{t-1}$ ' is the deviation from the moving average in the previous year.

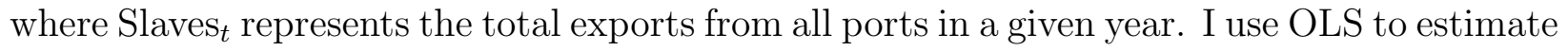
the persistent impact of these weather anomalies on the log of light intensity. Control variables include malaria suitability, presence of petroleum, distance to nearest foreign port, number of raster light intensity points within $500 \mathrm{~km}$, AEZ zone, absolute latitude, longitude, average 1902-1980 temperature, average deviation from 1902-1980 temperature across 18011866, average demeaned rainfall level across 1801-1866, and an average of the flood indicator across 1801-1866. Column (4) of Table 2 shows that positive rainfall shocks during periods of high slave trade activity in the 19th century are correlated with an increase in the level of development today. This corroborates previous studies, such as Nunn (2008), which demonstrate the persistent impact of the historical African slave trade on modern outcomes.

\section{$3.1 \quad$ Robustness}

Beyond including the impact of temperature, I perform various robustness checks to ensure the main relationship holds. In general, the negative relationship between rainfall and 
slave exports is stable, while the coefficient on temperature is more sensitive to changes in specification.

\subsubsection{Sample Restrictions}

One issue may be the time period examined. If West Africa exhibited excess rainfall or West-Central Africa exhibited a drought that coincided with the British abolition of the slave trade in 1807, the relationship between rainfall and slave exports could be coincidental, as the major slave exporting ports shifted south after the British abolition. Table A2 shows the results from restricting the sample to various decades. The results show no evidence that the British abolition is driving the results. In fact, the 1801 to 1810 decade is the only decade in which the coefficient on rainfall is positive, but statistically insignificant from zero. The coefficient on temperature fluctuates across decades between negative and positive values, though only the negative coefficients are significant at conventional levels.

Columns (1)-(3) of Table A3 show the results from restricting the sample to various geographic regions-West, West-Central, and East Africa-as defined by Figure A8. For rainfall, the coefficient is large and statistically significant at the one percent level for WestCentral Africa. On the other hand, the coefficient on rainfall in West Africa exhibits a smaller and insignificant negative relationship, while East Africa actually exhibits a large and statistically significant positive relationship. The results suggest that the interaction between rainfall and slave exports during this time period is being primarily driven by ports in West-Central Africa and the slave trade in Africa may operate under different mechanisms between West and East Africa. During this time period, the West-Central portion of Africa was the main producer of slaves and East Africa had a limited role, as depicted by Figure A7. The results for temperature show a similar pattern-being large and negative for WestCentral Africa, negative but smaller in magnitude for West Africa, and positive for East Africa.

Columns (4) and (5) of Table A3 show the results from restricting the sample to highexport ports (i.e., ports which exported more than 22,000 slaves during the time period) and low-export ports (i.e., ports which exported less than 100,000 slaves during the time period). Both of these regressions exhibit negative and statistically significant coefficients on rainfall, while the coefficients on temperature are negative, but statistically insignificant. 


\subsubsection{Specification and Estimation}

Another potential issue is the incidental parameter problem for fixed effects estimation in Tobit models. Greene (2002) shows that the incidental parameter problem primarily impacts the standard error estimates and that the bias decreases as time increases. In his simulations, Greene demonstrates that, with 20 time periods, the remaining bias is trivial for most applications. As I use over 60 time periods, the incidental parameter issue should be of little concern. However, Wooldridge $(2002,542)$ suggests using the port-specific mean for the climate variables instead of fixed effects as one potential solution to the incidental parameter problem. Column (1) of Table A4 shows the results from this regression. The rainfall coefficient on this regression maintains a similar magnitude and significance to the coefficient of my main result in Table 2. The temperature coefficient remains negative and insignificant.

Table A4 also shows the results from using OLS to estimate the model for port-years with positive slave exports, transforming the slave exports variable by using Log $\left(1+\right.$ Slaves $\left._{i t}\right)$, using conditional logit fixed effects to estimate the model with an indicator variable for positive slave exports, and estimating an OLS model on the sample of port-years with positive slave exports using first differences to account for the long time series panel. For all models, the rainfall coefficient maintains the same sign as in the Tobit model in Table 2 and is significant at conventional levels. The temperature coefficient varies in sign and significance across specifications.

Column (1) of Table A5 shows the results from normalizing the rainfall and temperature variables in each port by dividing by the standard deviation of each variable in the given port across the entire sample time period. ${ }^{12}$ While the negative coefficient on the temperature variable is not robust to this re-scaling, the coefficient on the rainfall variable remains negative and significant. Column (2) of Table A5 shows the results from dropping the flood indicator, which gives qualitatively similar conclusions as the results in Table 2. Column (3) of Table A5 uses a nonparametric bootstrap at the port-year level to estimate standard errors and gives similar conclusions regarding the precision of the estimates. Columns (4)-(6) of Table A5 replace the time fixed effects with port-specific linear time trends, linear and quadratic time trends, and linear and quadratic time trends in addition to year fixed effects

\footnotetext{
${ }^{12}$ Recall that the variables are already normalized to a within-port mean of zero.
} 
in the OLS model for port-years with positive slave exports. ${ }^{13}$ The coefficient on both rainfall and temperature remains negative, though at attenuated levels, when year fixed effects are excluded. When linear and quadratic time trends along with year fixed effects are included, the estimated impact of both temperature and rainfall increases along with the statistical significance. This suggests that flexibly controlling for annual shocks is important.

Finally, I test the sensitivity of my results to the geographic level of aggregation by changing the level of aggregation of slave exports to the region level. The results suggests that a negative rainfall or temperature shock in a region increases the number of slaves exported from across the entire region. The coefficients on both climate indicators are insignificant at conventional levels, which is to be expected with the reduced sample size. I also perform many of the other regressions reported in this paper at the region level and find my results are similar in sign, but not significance, to those at the port level. These region level results can be found in the online appendix.

\subsubsection{Measurement}

Measurement error is prominent with paleoclimate reconstructions. Furthermore, monthly or seasonal data would be preferable due to the differential impacts of climate on agriculture throughout the year. As long as the measurement error is uncorrelated with slave exports, the error will merely attenuate the coefficient estimates and bias the standard errors upwards. However, the classical measurement error assumption may not hold with paleoclimate reconstructions that use documentary evidence (such as the prevalence of famines in certain regions) to infer climate conditions, as these anecdotes may be correlated with non-climatic conditions (such as conflict). Regional substitution and spatial reconstruction of missing data may also be problematic.

Table A6 shows the sensitivity of the results to various methods of climate reconstruction. Columns (1)-(3) drop all observations created using regional substitution, spatial reconstruction, and regional substitution or spatial reconstruction respectively. The coefficient on rainfall is relatively stable across specifications, but less precisely estimated as the sample size decreases. Column (5) drops observations that are constructed without using within-region rainfall gauge or lake-level information to some extent. In this case, the coefficient is large, negative, and significant at conventional levels. Columns (6)-(8) use the mean

\footnotetext{
${ }^{13} \mathrm{I}$ do not do this for the Tobit model because of convergence issues.
} 
of all gauge-based, lake-based, and documentary-based information available in a region for a given year respectively. The gauge-based coefficient is negative, but insignificant, while the documentary-based coefficient is negative and significant at conventional levels. Only the coefficient for the lake-based rainfall measurement is positive, but insignificant from zero. Putting too much weight on differences across type of measurements should be cautioned against as the notes in Table A6 show there are strong differences in measurement types between West, West-Central, and East Africa. E.g., documentary-based reconstructions are dominant in West-Central Africa, which is the primary slave exporting region during this time, and there are no lake-based reconstructions for West-Central Africa. ${ }^{14}$ Overall, the table suggests the results are reasonably stable across the various measurement type restrictions.

\section{Mechanisms}

The lack of microdata on the manner in which each slave was acquired prevents pinning down the exact mechanism for the observed results. However, a combination of empirical exercises and anecdotal examination can show the relative strengths of four non-mutually exclusive hypotheses: interethnic group conflict, household desperation, the domestic African slave market, and inventory responses to epidemics.

\subsection{Interethnic Group Conflict}

Conflict is believed to be the largest producer of slaves during the trans-Atlantic slave trade (Lovejoy, 2012, 85). Entire conquered nations would be sold for export as a part of 'eating the nation.' Other conquered nations would be required to pay continual tribute in slaves (Sparks, 2014, 124-129). However, warfare also closed the trade routes between the interior and the coast causing the supply of slaves to temporarily decrease before the conflict ended and the newly captured slaves hit the market. The deadly rivalry between the Fante and the Asante along the Gold Coast and the associated accounts at the port of Annamaboe provide one such example of the temporal dynamics of warfare and slave exports (Sparks, $2014,92) \cdot{ }^{15}$

\footnotetext{
${ }^{14}$ Regions near lakes may also be less susceptible to rainfall shocks.

${ }^{15}$ This is one plausible mechanism for the time lag in rainfall's impact.
} 
Table 4: Droughts and Conflict in 19th Century Africa

\begin{tabular}{|c|c|c|c|c|c|c|}
\hline & \multicolumn{6}{|c|}{ Dependent Variable: Indicator for Conflict } \\
\hline & \multicolumn{2}{|c|}{$\underline{100 \mathrm{~km}}$} & \multicolumn{2}{|c|}{$\underline{250 \mathrm{~km}}$} & \multicolumn{2}{|c|}{$\underline{500 \mathrm{~km}}$} \\
\hline & $(1)$ & $(2)$ & $(3)$ & (4) & $(5)$ & $(6)$ \\
\hline $\operatorname{Rain}_{t-1}$ & $\begin{array}{l}-0.120 \\
(0.033)\end{array}$ & & $\begin{array}{l}-0.103 \\
(0.025)\end{array}$ & & $\begin{array}{c}0.044 \\
(0.025)\end{array}$ & \\
\hline Flood $_{t-1}$ & $\begin{array}{c}0.766 \\
(0.207)\end{array}$ & & $\begin{array}{c}0.555 \\
(0.170)\end{array}$ & & $\begin{array}{c}0.114 \\
(0.154)\end{array}$ & \\
\hline $\operatorname{Rain}_{t}$ & & $\begin{array}{c}-0.101 \\
(0.032)\end{array}$ & & $\begin{array}{l}-0.143 \\
(0.025)\end{array}$ & & $\begin{array}{l}-0.025 \\
(0.024)\end{array}$ \\
\hline Flood $_{t}$ & & $\begin{array}{c}0.568 \\
(0.213)\end{array}$ & & $\begin{array}{c}0.413 \\
(0.184)\end{array}$ & & $\begin{array}{c}0.208 \\
(0.173)\end{array}$ \\
\hline $\operatorname{Temp}_{t}$ & $\begin{array}{l}-1.207 \\
(0.483)\end{array}$ & $\begin{array}{c}-0.616 \\
(0.449)\end{array}$ & $\begin{array}{l}-0.968 \\
(0.345)\end{array}$ & $\begin{array}{l}-0.558 \\
(0.344)\end{array}$ & $\begin{array}{l}-0.020 \\
(0.287)\end{array}$ & $\begin{array}{l}-0.007 \\
(0.295)\end{array}$ \\
\hline Port F.E. & Yes & Yes & Yes & Yes & Yes & Yes \\
\hline Year F.E. & Yes & Yes & Yes & Yes & Yes & Yes \\
\hline Obs. & 2268 & 2268 & 4032 & 4032 & 5656 & 5656 \\
\hline
\end{tabular}

Notes: Probit regressions with port and year fixed effects and robust standard errors in parentheses. Dependent variable is an indicator for whether a conflict occurred within $\mathrm{X} \mathrm{km}$ of the port in a given year. For Columns (1) and (2), the distance threshold is $100 \mathrm{~km}$. For Columns (3) and (4), the distance threshold is $250 \mathrm{~km}$. For Columns (5) and (6), the distance threshold is $500 \mathrm{~km}$. Coefficients are reported.

Both contemporary and historical evidence suggest a strong correlation between droughts and conflict (Calderone, Maystadt and You, 2015; Hsiang, Burke and Miguel, 2013; Miller, 1982; Lovejoy, 2012, 69). In some regions, such as in Angola, the population's faith in its ruler rested on the ruler's ability to control the rains. Periods of drought led to increased conflict along the African coast, as military campaigns would be mounted by kings and chiefs trying to preserve their kingdom and image (Miller, 1982). The Islamic regions of Africa also exhibited a strong connection between war and drought (Lovejoy, 2012, 69).

The Imbangala are an example of a group that altered the allocation of their labor in response to long-run changes in climate conditions. The Imbangala were a band of raiders that emerged in the late 16th century in the Angolan region of West-Central Africa. Their emergence corresponds with a prolonged period of drought in the region. While the timing of the emergence of the Imbangala could be considered a coincidence, Miller (1982) traces 
Table 5: Droughts and Conflict in 19th Century Africa - Trends and Shocks

\begin{tabular}{lcccccc}
\hline \multicolumn{7}{c}{ Dependent Variable: Indicator for Conflict } \\
& \multicolumn{2}{c}{$100 \mathrm{~km}$} & \multicolumn{2}{c}{$250 \mathrm{~km}$} & \multicolumn{2}{c}{$500 \mathrm{~km}$} \\
& $(1)$ & $(2)$ & $(3)$ & $(4)$ & $(5)$ & $(6)$ \\
\hline Rain Trend $t$ & -0.083 & -0.126 & -0.149 & -0.224 & -0.105 & -0.099 \\
& $(0.048)$ & $(0.051)$ & $(0.038)$ & $(0.041)$ & $(0.037)$ & $(0.038)$ \\
Rain Shock $t_{-1}$ & -0.056 & & -0.039 & & 0.072 & \\
& $(0.032)$ & & $(0.024)$ & & $(0.023)$ & \\
Rain Shock $t$ & & -0.057 & & -0.106 & & -0.011 \\
& & $(0.031)$ & & $(0.025)$ & & $(0.023)$ \\
Temp Trend $t$ & -1.063 & -1.286 & -0.947 & -1.058 & 1.214 & 1.558 \\
& $(0.960)$ & $(0.942)$ & $(0.714)$ & $(0.710)$ & $(0.608)$ & $(0.594)$ \\
Temp Shock & -1.213 & -1.118 & -0.995 & -0.977 & -0.261 & -0.374 \\
& $(0.496)$ & $(0.498)$ & $(0.370)$ & $(0.379)$ & $(0.299)$ & $(0.300)$ \\
\hline Port F.E. & Yes & Yes & Yes & Yes & Yes & Yes \\
Year F.E. & Yes & Yes & Yes & Yes & Yes & Yes \\
Obs. & 2226 & 2268 & 3960 & 4032 & 5555 & 5656 \\
\hline
\end{tabular}

Notes: Probit regressions with port and year fixed effects and robust standard errors in parentheses. Dependent variable is an indicator for whether a conflict occurred within $\mathrm{X}$ $\mathrm{km}$ of the port in a given year. For Columns (1) and (2), the distance threshold is $100 \mathrm{~km}$. For Columns (3) and (4), the distance threshold is $250 \mathrm{~km}$. For Columns (5) and (6), the distance threshold is $500 \mathrm{~km}$. 'Rain Trend $_{t}$ ' is a 5 -year moving average of the previous rainfall levels. 'Rain Shock ${ }_{t-1}$ ' is the deviation from the 5-year moving average in the previous year. 'Temp Trend ${ }_{t}$ ' and 'Temp Shock $t^{\prime}$ are defined analogously. Coefficients are reported.

the intricate relationship between the Imbangala and the drought. Beyond the timing of the Imbangala's presence, their cultural practices also reflect drought-induced desperation. These practices include cannibalism, felling stands of palm trees, and a perverse mockery of the traditional ceremonies associated with the local rain kings. Their descendants were also one of the few cultural groups to preserve an oral history of the drought. While most African societies were based upon kinship, the Imbangala operated as a 'warrior fraternity' which accepted new members through initiation ceremonies (Miller, 1976, 232-3). This allowed desperate individuals to join the warrior band in an attempt to avoid droughtinduced famines. The ability to add new recruits to their ranks was a large contributing factor to the success of the Imbangala (Miller, 1976, 237). When the drought ended and the 
rains returned, groups of the Imbangala began to integrate back into the more sedentary population and returned to their agricultural roots. Oral stories from their descendants note the return of the rain as a reason for this resettlement (Miller, 1982).

To examine this empirically, I use a geocoded dataset on conflicts in Africa from 1801 to 1866. The original data comes from Brecke (1999). ${ }^{16}$ I exclude all conflicts that include non-African continental actors. Figure A10 plots the location of the conflicts in the sample. For each port and year, I create an indicator variable that takes on the value of one if there exists an ongoing conflict within $X \mathrm{~km}$ where I vary $X$ from 100 to 250 to $500 \mathrm{~km}$. I then run a probit regression using heteroskedastic robust standard errors and otherwise similar specifications as in Table 2 and Table 3. If rainfall and temperature impact the slave trade through increased conflict, we'd expect to see negative coefficients. In Table 4, we see the impact of both the temporal lag and the contemporary rainfall variable is negative and significant for the $100 \mathrm{~km}$ and $250 \mathrm{~km}$ radii. At $500 \mathrm{~km}$, the coefficients on the rainfall variables are smaller in magnitude and insignificant. This suggests that climate conditions at a single port are not strong predictors of conflict across the entire $500 \mathrm{~km}$ radius, but they are strong predictors for smaller radii. Consistent with Iyigun, Nunn and Qian (2017), temperature has a negative coefficient with varied magnitude and significance across specifications; again, we see a stronger relationship for the smaller radii. Table 5 uses the five-year moving average of each climate variable and the deviations from these moving averages. For rainfall, we see a negative and significant coefficient on the trend variable across specifications, while the shock variable exhibits a similar pattern as in Table 4. For temperature, we see an insignificant, negative relationship for the trend variable across the $100 \mathrm{~km}$ and $250 \mathrm{~km}$ radii and a similar pattern as in Table 4 for the shock variable.

Table A7 is similar to Tables 4 and 5, except that it aggregates the data at the rainfall region level and compares regions with slave ports to regions without slave ports. Across specifications, we see a negative relationship between rainfall variables and conflict in the slave exporting regions, though with varied significance. On the other hand, we often see a positive, insignificant relationship between the rainfall variables and conflict in the non-slave exporting regions. When we do see a negative coefficient on rainfall for the non-slave exporting regions, is is of much smaller magnitude than the coefficient for the slave exporting regions. Qualitatively similar conclusions can be drawn when comparing the coefficients on

\footnotetext{
${ }^{16}$ I use the geocoded data from Fenske and Kala (2017).
} 
temperature between the slave and non-slave exporting regions of Africa. While interpreting these results as causal is difficult, they are suggestive that the slave trade may have fundamentally altered the incentives to participate in conflict. At a minimum, they show that slave exporting regions responded differently to climate shocks in the 19th century, regardless of whether this difference existed before the slave trade.

\subsection{Household Desperation}

Climate shocks also lead to income shocks. During a severe drought, the opportunity costs of not increasing participation in the slave trade may be starvation. In the absence of other methods to smooth consumption over prolonged periods, individuals may be forced to specialize to the point of self-selecting themselves, their friends, or their family members into the slave trade to prevent starvation. In one sample of freed slaves in Sierra Leone, nearly 20 percent of the former slaves were tricked or sold by a friend or relative into the slave trade (Nunn, 2012).

One form of household desperation is the sale of pawned Africans into the slave trade. African societies developed a unique form of collateral during the slave trade which they called 'pawning'. To pawn an individual meant that he or she would be used as collateral for a debt obligation. The pawn, often a child, would live with the creditor and was required to perform any labor requested by the creditor (Lovejoy, 2012, 13). Ship captains would often enter these arrangements by giving trade goods to African merchants who would then exchange the goods for slaves in the interior. If the African merchant was unable to fulfill the contractual obligations set forth by delivering the requested trade goods before the deadline, then the creditor had the right to sell the pawn into slavery (Sparks, 2014, 27-8).

A custom related to pawning is the practice of panyarring, which was common along the Gold Coast (Sparks, 2014, 138). To panyar means to capture a slave away from the battlefield. This practice includes capturing enemy caravans, but also applies to kidnapping a debtor or his kinsmen to force repayment. If repayment could not be made, the captured individual would be sold into slavery. Bush traders were also prevalent. These individuals specialized in kidnapping free Africans along the coast, typically children, and selling them to ship captains before their relatives could free them (Sparks, 2014, 135). Captains of slave ships would withhold payment until immediately before sailing, as the kidnapped slaves would often be redeemed when their relatives realized what had happened. Being a bush 
trader did not come without risks. Any individual caught kidnapping free Africans was liable to be sold into slavery himself or killed in retribution. Economic hardships would make individuals more likely to engage in this kidnapping behavior. Furthermore, as hardtimes made it difficult to repay debts, defaults on extended credit would increase and lead to a subsequent increase in kidnapped and pawned African slave exports. Internal migration to coast regions during droughts and famines would further reduce the costs of acquiring slaves through panyarring or similar practices.

Benguela, a port located on the coast of present-day Angola and one of the most important ports during the trans-Atlantic slave trade, provides a prime example of this household desperation behavior. Between 1837 and 1841, the region surrounding Benguela suffered a severe drought. This led to an influx of migrants seeking refuge and food (Dias, 1981). Migrants, whether fleeing raiders or fleeing droughts, often became slaves themselves and took up positions of servitude in order to survive economic hardships (Behrendt, Latham and Northrup, 2010, 110). This can be thought of as an extreme form of consumption smoothing as individuals exchanged their freedom in return for a guaranteed level of consumption. Miller (1982) notes that the practice of refugees becoming slaves in return for sustenance was common across African ports and re-invigorated the slave trade in these locales. In addition to exchanging their freedom for food, migrants were also vulnerable to kidnappings and other forms of violence. Leaving one's home meant leaving the social ties that helped provide protection against kidnappings. The use of kidnapping was particularly prominent along the Angolan coast and the increased availability of unprotected migrants would have allowed the practice to flourish during droughts (Candido, 2013, 18).

Other locations along the Angolan coast exhibited similar responses to periods of low rainfall. In 1857, after a two-year drought in Kisama, migrants flooded the markets in Kwanza exchanging themselves and their children for grain. Locals from the surrounding area flocked to the markets to take advantage of the surplus of slaves, many of them children sold by their relatives, at substantially reduced prices (Dias, 1981). Despite occurring during the waning moments of the Atlantic slave trade, many of these refuges found themselves on European slave ships headed for the Caribbean.

A similar event occurred in the Novo Redondo portion of Angola in the late 1870s (Dias, 1981). Again, desperate households resorted to selling themselves or their relatives into slavery in an effort to survive. The magnitude of desperation resulted in a shipment of 
512 people to São Tomé by the Banco Natacional Ultramarino's recruiters in October 1877, when typical shipments were half this size. Similar events are recorded to have happened in response to climate shocks as late as the 1920s in the Dande and Zaire river regions (Dias, 1981).

One way to examine this mechanism empirically is to see if the child ratio increases during droughts because children were the most vulnerable to being sold by relatives, being pawned, or being kidnapped. To do this, I use data from the African Names Database ${ }^{17}$ which contains individual slave demographic data (including age and gender) of 91,491 Africans taken from ships caught in illegal slave trade activities after the 1807 Slave Trade Act. This data contains the primary port of purchase in Africa which allows it to be linked to the rest of my data. I then run a probit model with an indicator for whether a given individual is less than 15 years old and cluster standard errors at the port level. Columns (1) and (2) of Table 6 show the results when using five-year moving averages for each climate variable and the deviation from these averages. The coefficient on rainfall is negative across specifications with varying significance and the previous year's rainfall shock is marginally insignificant. The temperature coefficients are also negative across specifications and often significant at conventional levels. These results provide preliminary empirical support that household desperation may be contributing to the increase in slave exports in response to droughts. Furthermore, the African Names Database primarily contains slaves exported from West Africa (the region controlled by the British), while anecdotal and empirical evidence suggests that the drought-slave relationship may have been strongest in the West-Central region during this time period. This difference in sample suggests these results may be conservative.

\subsection{Domestic African Slave Market}

Captured slaves were not always exported from Africa, but were often kept domestically during this time period. The owners of domestic slaves must continually make the decision as to whether they should continue to use their slaves in domestic production (whether agricultural, household, or sexual production) or sell their slaves for export. As climate conditions reduce the economic returns to agriculture, owners will be more likely to sell their

\footnotetext{
${ }^{17}$ As of October 12, 2016, the data can be downloaded from http://www.slavevoyages.org/voyage/ download
} 
Table 6: Other Mechanisms

\begin{tabular}{|c|c|c|c|c|c|c|}
\hline & \multicolumn{2}{|c|}{$\frac{\text { Household Desperation }}{\text { Child Indicator }}$} & \multicolumn{2}{|c|}{$\frac{\text { Domestic Market }}{\text { Male Indicator }}$} & \multicolumn{2}{|c|}{$\frac{\text { Inventory \& Epidemics }}{\text { Voyage Mortality }}$} \\
\hline & (1) & $(2)$ & $(3)$ & (4) & $(5)$ & (6) \\
\hline Prediction: & - & - & + & + & - & - \\
\hline Rain Trend $_{t}$ & $\begin{array}{l}-0.018 \\
(0.048)\end{array}$ & $\begin{array}{l}-0.024 \\
(0.047)\end{array}$ & $\begin{array}{c}0.012 \\
(0.044)\end{array}$ & $\begin{array}{c}0.006 \\
(0.046)\end{array}$ & $\begin{array}{c}0.024 \\
(0.005)\end{array}$ & $\begin{array}{c}0.024 \\
(0.006)\end{array}$ \\
\hline Rain Shock $_{t-1}$ & $\begin{array}{l}-0.054 \\
(0.035)\end{array}$ & & $\begin{array}{c}0.033 \\
(0.036)\end{array}$ & & $\begin{array}{c}0.001 \\
(0.004)\end{array}$ & \\
\hline Rain Shock $_{t}$ & & $\begin{array}{l}-0.032 \\
(0.028)\end{array}$ & & $\begin{array}{l}-0.035 \\
(0.036)\end{array}$ & & $\begin{array}{l}-0.003 \\
(0.004)\end{array}$ \\
\hline Temp $_{\text {Trend }}$ & $\begin{array}{l}-2.080 \\
(0.680)\end{array}$ & $\begin{array}{l}-2.019 \\
(0.846)\end{array}$ & $\begin{array}{l}-3.018 \\
(1.298)\end{array}$ & $\begin{array}{l}-2.957 \\
(1.313)\end{array}$ & $\begin{array}{l}-0.322 \\
(0.143)\end{array}$ & $\begin{array}{l}-0.293 \\
(0.126)\end{array}$ \\
\hline Temp Shock & $\begin{array}{l}-0.687 \\
(0.461)\end{array}$ & $\begin{array}{l}-0.902 \\
(0.477)\end{array}$ & $\begin{array}{l}-0.857 \\
(0.610)\end{array}$ & $\begin{array}{l}-0.854 \\
(0.573)\end{array}$ & $\begin{array}{l}-0.070 \\
(0.041)\end{array}$ & $\begin{array}{l}-0.044 \\
(0.040)\end{array}$ \\
\hline Port F.E. & Yes & Yes & Yes & Yes & Yes & Yes \\
\hline Year F.E. & Yes & Yes & Yes & Yes & Yes & Yes \\
\hline Obs. & 65415 & 65415 & 65423 & 65423 & 2033 & 2088 \\
\hline
\end{tabular}

Notes: Columns (1)-(4) are probit regressions at the individual slave level with standard errors clustered by port. Dependent variable in Columns (1) and (2) is an indicator for whether the recorded age is less than 15 years old. Dependent variable in Columns (3) and (4) is an indicator for whether the individual is a male. Coefficients are plotted in Columns (1)-(4). Columns (5) and (6) are OLS regressions with standard errors clustered at the port level with the dependent variable being a given voyage's slave mortality rate from embarkation to departure. Trend variables are 5-year moving averages and shocks are the deviation from the trend.

slaves used for agricultural production. Domestic slave ownership can also be modeled as a buffer stock that operates as a form of consumption smoothing in the face of volatile income and credit constraints (Rosenzweig and Wolpin, 1993).

While males were typically exported from Africa, the internal slave market in Africa placed a higher premium on females (Geggus, 1989). Klein $(1997,36)$ says that:

...scholars talk of the vital importance of female agricultural labor in West Africa, while some also stress that in those societies where polygyny was important, the role of slave wives was crucial... The shipping of more women than normal might indicate a fundamental breakdown in the economic or social viability of the state. [emphasis added] 
Therefore, if the domestic slave market is responding to negative climate shocks, we'd expect to see an increase in female slave exports during droughts. I examine this mechanism in a manner similar to the examination of the household desperation hypothesis with the African Names Database. Using an indicator for whether a slave is male and a probit model with standard errors clustered at the port level, Columns (3) and (4) of Table 6 give no strong evidence that females are more likely to be exported during drought conditions. Furthermore, we see a negative and significant relationship between temperature and the likelihood of a slave export being male, which is contrary to the hypothesis. Most anecdotal evidence points towards West Africa as highly valuing female slaves, not West-Central Africa. Given that the African Names Database comes primarily from West Africa, this provides further evidence that the domestic African slave market is not driving the slave trade response to climate conditions.

\subsection{Inventory Responses to Epidemics}

Major droughts lead to famines and mass internal migrations (Dias, 1981). The combination of malnutrition and migration increased the local population's susceptibility to diseases, particularly European diseases such as smallpox. Anecdotal evidence suggests that while Africans primarily suffered from European diseases during periods of drought, Europeans primarily suffered from African diseases during periods of increased rainfall (Miller, 1982). Miller (1982) argues that:

Epidemics generally tended to promote rather than to retard the flow of slaves. When sickness threatened the lives of captives waiting in the port towns, slavers disposed of their accumulated holdings to avoid the cost of increased mortality. Since the early days of slaving in Angola, traders had prided themselves in their skill in exchanging sick and dying slaves for less perishable forms of property during epidemics.

If the increase in exports are in response to epidemics, we'd expect slave mortality to be negatively correlated with rainfall. To examine this, I use the voyage mortality rates for all voyages in the Slave Voyages $^{18}$ that have non-missing mortality and can be mapped to a

\footnotetext{
${ }^{18}$ Data comes from the 2016 revision of the Slave Voyages extended data set http://www. slavevoyages . org/voyage/download.
} 
primary port of embarkation in Africa, which I use to map climate variables to each voyage. I then perform OLS and cluster standard errors at the port level in an otherwise similar specification to Table 3. The results shown in Columns (5) and (6) of Table 6 suggest that slave mortality is positively correlated with trends in rainfall, and this relationship is significant at conventional levels. For temperature, we see a negative and significant relationship. However, the relationship between temperature and epidemics during this time period is ambiguous (particularly when accounting for the abnormally cool climate conditions). Overall, these findings suggest that the inventory response to epidemics is not driving the drought-slave trade relationship.

\subsection{Unifying Framework}

The empirical results above suggest that conflict and household desperation are the two most likely mechanisms for the impact of droughts on slave exports, which is consistent with anecdotal evidence. While the above results indicate the manner in which the slaves were acquired, they largely ignore the economic rational that induced the changes in behavior.

There are two primary ways climate can impact the economic incentives of the slave trade. First, it can alter the explicit costs of acquiring slaves. This is the focus of Fenske and Kala (2015) when they explain the negative relationship between slave exports and temperature. Second, climate conditions can impact the opportunity cost of participating in the slave trade. As droughts reduce agricultural output, the opportunity costs of participating in the slave trade decrease. Prolonged droughts can cause long-run shifts in labor allocation towards slave trade activities, such as conflict and panyarring. Short-run climate fluctuations also alter the opportunity cost to migration, selling family members into slavery, and similar consumption smoothing behaviors. Both the increase in conflict and the increase in household desperation behaviors in response to droughts are likely caused by changes in the opportunity cost of participating in the slave trade.

In the Online Appendix, I formalize and expand on this discussion by incorporating opportunity costs into the model used within Fenske and Kala (2015). 


\section{Conclusion}

Negative rainfall shocks and droughts increased the number of slaves exported from the corresponding region, which confirms the hypothesis proposed by historians of the African slave trade (Miller, 1982; Dias, 1981; Newitt, 1995; Lovejoy, 2012). Likewise, negative temperature shocks also appear to have increased slave exports. Brooks (2003, 102-3) suggests that the period from 1630 to 1860 was a relatively dry period in Africa's history. Furthermore, the slave exporting regions of Africa likely experienced their own 'Little Ice Age' during this same time period. These two suggestions imply that a non-trivial amount of the total number of slaves exported from Africa may be attributed to climate conditions in Africa. To be clear, these conclusions do not abrogate the ethical responsibility of non-Africans for the slave trade - absent a non-vertical demand curve for slaves by non-Africans, these results would not be possible. However, the importance of supply-side considerations in determining the level of slave exports from Africa should not be discounted.

These supply-side responses to climate conditions likely included increased conflict and measures of household desperation, such as selling family members into slavery. The fact that the drought-conflict relationship is strongest in the slave exporting regions of Africa suggests that the slave trade may have altered the opportunity costs of engaging in conflict in response to climate conditions. If this relationship has persisted, then some of Africa's contemporary propensity for conflict may be attributed to the historical slave trade. Future research should continue to examine the contemporary implications of these findings. 


\section{References}

Adhvaryu, Achyuta, Namrata Kala, and Anant Nyshadham. 2015. "Booms, Busts, and Household Enterprise: Evidence from Coffee Farmers in Tanzania." Working Paper.

Barrios, Salvador, Bazoumana Ouattara, and Eric Strobl. 2008. "The Impact of Climatic Change on Agricultural Production: Is it Different for Africa?" Food Policy, 33(4): 287-298.

Behrendt, Stephen, A.J.H. Latham, and David Northrup. 2010. The Diary of Antera Duke, an Eighteenth-Century African Slave Trader. Oxford University Press.

Brecke, Peter. 1999. "Violent Conflicts 1400 A.D. to the Present in Different Regions of the World." Paper prepared for the 1999 Meeting of the Peace Science Society (International) in Ann Arbor, Michigan.

Brooks, George E. 2003. Eurafricans in Western Africa: Commerce, Social Status, Gender, and Religious Observance from the Sixteenth to the Eighteenth Century. James Currey.

Calderone, Margherita, Jean-Francois Maystadt, and Liangzhi You. 2015. "Local Warming and Violent Conflict in North and South Sudan." Journal of Economic Geography, 15(3): 649-171.

Candido, Mariana P. 2013. An African Slaving Port in the Atlantic World: Benguela and its Hinterland. New York:Cambridge University Press.

Corno, Lucia, and Alessandra Voena. 2015. "Selling Daughters: Age at Marriage, Income Shocks and Bride Price Tradition." Working Paper.

Crost, Benjamin, Claire Duquennois, Joseph H. Felter, and Daniel I. Rees. 2015. "Climate Change, Agricultural Production and Civil Conflict: Evidence from the Phillipines." Working Paper.

Curtin, Philip D. 1975. Economic Change in Precolonial Africa: Senegambia in the Era of the Slave Trade. University of Wisconsin Press.

Dalton, John T., and Tin Cheuk Leung. 2014. "Why is Polygyny More Prevalent in Western Africa?: An African Slave Trade Perspective." Economic Development and Cultural Change, 62(4): 599-632.

Dalton, John T., and Tin Cheuk Leung. 2015a. "Being Bad by Being Good: Captains, Managerial Ability, and the Slave Trade." Working Paper.

Dalton, John T., and Tin Cheuk Leung. 2015b. "Dispersion and Distortions in the Trans-Atlantic Slave Trade." Journal of International Economics, 96(2): 412-425.

Dias, Jill R. 1981. "Famine and Disease in the History of Angola c. 1830-1930." The Journal of African History, 22(3): 349-378. 
Eltis, David, Stephen Behrendt, David Richardson, and Herbert Klein. 1999. "The Trans-Atlantic Slave Trade: A Database on CD-ROM."

Fenske, James, and Namrata Kala. 2015. "Climate and the Slave Trade." Journal of Development Economics, 112: 19-32.

Fenske, James, and Namrata Kala. 2017. "1807: Economic Shocks, Conflict and the Slave Trade." Journal of Development Economics, 126: 66-76.

Geggus, David. 1989. "Sex Ratio, Age and Ethnicity in the Atlantic Slave Trade: Data from French Shipping and Plantation Records." The Journal of African History, 30(1): 2344 .

Greene, William. 2002. "The Bias of the Fixed Effects Estimator in Nonlinear Models." Working Paper.

Hoogeveen, Johannes, Bas Van Der Klaauw, and Gijsbert Van Lomwel. 2011. "On the Timing of Marriage, Cattle, and Shocks." Economic Development and Cultural Change, 60(1): 121-154.

Hsiang, Solomon M., Marshall Burke, and Edward Miguel. 2013. "Quantifying the Influence of Climate on Human Conflict." Science, 341.

Iyigun, Murat, Nathan Nunn, and Nancy Qian. 2017. "Winter is Coming: The LongRun Effects of Climate Change on Conflict, 1400-1900." Working Paper.

Jappelli, Tullio, and Luigi Pistaferri. 2010. "The Consumption Response to Income Changes." Annual Review of Economics, 2(1): 479-506.

Klein, Herbert S. 1997. "African women in the Atlantic slave trade." In Women and Slavery in Africa. , ed. Claire Robertson and Martin A. Klein, Chapter African Wo.

Kurukulasuriya, Pradeep, and Robert Mendelsohn. 2008. "A Ricardian Analysis of the Impact of Climate Change on African Cropland." African Journal of Agricultural and Resource Economics, 2(1).

Lovejoy, Paul E. 2012. Transformations in Slavery: A History of Slavery in Africa. New York:Cambridge University Press.

Lovejoy, Paul E., and David Richardson. 1995. "British Abolition and its Impact on Slave Prices Along the Atlantic Coast of Africa, 1783-1850." Journal of Economic History, 55(1): 98-119.

Mann, Michael E., Raymond S. Bradley, and Malcolm K. Hughes. 1998. "GlobalScale Temperature Patterns and Climate Forcing over the Past Six Centuries." Nature, 392(6995): 779-787. 
Mann, Michael E., Zhihua Zhang, Scott Rutherford, Raymond S. Bradley, Malcolm K. Hughes, Drew Shindell, Caspar Ammann, Greg Faluvegi, and Fenbiao Ni. 2009. "Global Signatures and Dynamical Origins of the Little Ice Age and Medieval Climate Anomaly." Science, 326(5957): 1256-1260.

Miller, Joseph C. 1976. Kings and Kinsmen: Early Mbundu States in Angola. Oxford University Press.

Miller, Joseph C. 1982. "The Significance of Drought, Disease and Famine in the Agriculturally Marginal Zones of West-Central Africa." Journal of African History, 23(1): 17-61.

Morduch, Jonathan. 1995. "Income Smoothing and Consumption Smoothing." Journal of Economic Perspectives, 9(3): 103-114.

Newitt, Malyn. 1995. A History of Mozambique. C. Hurst \& Co.

Nicholson, Sharon E. 1986. "The Spatial Coherence of African Rainfall Anomalies: Interhemispheric Teleconnections." Journal of Climate and Applied Meteorology, 25(10): 13551381.

Nicholson, Sharon E. 2001. "A Semi-Quantitative, Regional Precipitation Data Set for Studying African Climates of the Nineteenth Century, Part I. Overview of the Data Set." Climatic Change, 50(3): 317-353.

Nicholson, Sharon E., David J. Nash, Brian M. Chase, Sefan W. Grab, Timothy M. Shanahan, Dirk Verschuren, Asfawossen Asrat, Anne-Marie Lézine, and Mohammad Umer. 2013. "Temperature Variability Over Africa During the Last 2000 Years." The Holocene, 23(8): 1085-1094.

Nunn, Nathan. 2008. "The Long-Term Effects of Africa's Slave Trades." Quarterly Journal of Economics, 123(1): 139-176.

Nunn, Nathan. 2012. "74th IAES Conference Keynote Address."

Nunn, Nathan, and Diego Puga. 2012. "Ruggedness: The Blessing of Bad Geography in Africa." Review of Economics and Statistics, 94(1): 20-36.

Nunn, Nathan, and Leonard Wantchekon. 2011. "The Slave Trade and the Origins of Mistrust in Africa." American Economic Review, 101(7): 3221-3252.

Obikili, Nonso. 2015. "The Impact of the Slave Trade on Literacy in West Africa: Evidence from the Colonial Era." Journal of African Economies, 25(1): 1-55.

Reyburn, Rita, Deok Ryun Kim, Michael Emch, Ahmed Khatib, Lorenz Von Seidlein, and Mohammad Ali. 2011. "Climate Variability and the Outbreaks of Cholera in Zanzibar, East Africa: A Time Series Analysis." American Journal of Tropical Medicine and Hygiene, 84(6): 862-869. 
Rosenzweig, Mark R., and Kenneth I. Wolpin. 1993. "Credit Market Constraints, Consumption Smoothing, and the Accumulation of Durable Production Assets in Low-Income Countries: Investments in Bullocks in India." Journal of Political Economy, 101(2): 223.

Rosenzweig, Mark R., and Oded Stark. 1989. "Consumption Smoothing, Migration, and Marriage: Evidence from Rural India." Journal of Political Economy, 97(4): 905.

Sekhri, Sheetal, and Adam Storeygard. 2014. "Dowry Deaths: Response to Weather Variability in India." Journal of Development Economics, 111: 212-223.

Sparks, Randy. 2014. Where the Negroes are Masters: An African Port in the Era of the Slave Trade. Harvard University Press.

Whatley, Warren. Forthcoming. "The Gun-Slave Cycle in the 18th Century British Slave Trade." Explorations in Economic History.

Whatley, Warren, and Rob Gillezeau. 2011. "The Impact of the Transatlantic Slave Trade on Ethnic Stratification in Africa." American Economic Review: Papers and Proceedings, 101(3): 571-576.

Wooldridge, Jeffrey M. 2002. Econometric Analysis of Cross Section and Panel Data. Cambridge, MA:MIT Press.

Zeleza, Paul Tiyambe. 1997. A Modern Economic History of Africa. East African Educational Publishers.

Zhou, Guofa, Noboru Minakawa, Andrew K. Githeko, and Guiyun Yan. 2004. "Association Between Climate Variability and Malaria Epidemics in the East African Highlands." Proceedings of the National Academy of Sciences of the United States of America, 101(8): 2375-2380. 


\section{Appendix: A}

Table A1: Summary Statistics

\begin{tabular}{|c|c|c|c|c|c|}
\hline Variable & Mean & Std. Dev. & Min. & Max. & Obs. \\
\hline Slave Exports & 410.2 & 1947.4 & 0.0 & 34927.3 & 8118 \\
\hline Rainfall (demeaned) & 0.000 & 1.587 & -3.288 & 4.364 & 8118 \\
\hline Gauge-based Rainfall (demeaned) & 0.375 & 1.503 & -1.530 & 4.076 & 883 \\
\hline Document-based Rainfall (demeaned) & -0.519 & 1.715 & -3.288 & 3.182 & 1394 \\
\hline Lake-based Rainfall (demeaned) & 0.475 & 1.843 & -3.015 & 2.985 & 965 \\
\hline Weighted Rainfall & -0.001 & 0.032 & -1.369 & 1.488 & 8118 \\
\hline Flood Indicator & 0.020 & 0.141 & 0.000 & 1.000 & 8118 \\
\hline Gauge-based Flood Indicator & 0.037 & 0.190 & 0.000 & 1.000 & 883 \\
\hline Document-based Flood Indicator & 0.016 & 0.127 & 0.000 & 1.000 & 1394 \\
\hline Lake-based Flood Indicator & 0.000 & 0.000 & 0.000 & 0.000 & 965 \\
\hline Weighted Flood & 0.002 & 0.037 & 0.000 & 2.585 & 8118 \\
\hline Temperature (demeaned) & 0.000 & 0.128 & -0.713 & 0.676 & 8118 \\
\hline Weighted Temperature & -0.000 & 0.006 & -0.432 & 0.001 & 8118 \\
\hline 5-Year MA Rainfall & 0.042 & 0.815 & -2.688 & 2.764 & 7503 \\
\hline 5-Year MA Temperature & 0.002 & 0.077 & -0.325 & 0.350 & 7503 \\
\hline Deviation from Rainfall's 5-Year MA & -0.025 & 1.715 & -5.000 & 4.600 & 7503 \\
\hline Deviation from Temperature's 5-Year MA & -0.005 & 0.129 & -0.833 & 0.667 & 7503 \\
\hline 10-Year MA Rainfall & 0.031 & 0.623 & -2.148 & 1.924 & 6888 \\
\hline 10-Year MA Temperature & 0.001 & 0.063 & -0.279 & 0.291 & 6888 \\
\hline Deviation from Rainfall's 10-Year MA & 0.017 & 1.607 & -4.500 & 4.600 & 6888 \\
\hline Deviation from Temperature's 10-Year MA & -0.005 & 0.138 & -0.785 & 0.543 & 6888 \\
\hline 20-Year MA Rainfall & 0.032 & 0.405 & -1.498 & 1.312 & 5658 \\
\hline 20-Year MA Temperature & -0.001 & 0.040 & -0.143 & 0.132 & 5658 \\
\hline Deviation from Rainfall's 20-Year MA & -0.018 & 1.628 & -4.600 & 4.650 & 5658 \\
\hline Deviation from Temperature's 20-Year MA & 0.012 & 0.136 & -0.677 & 0.616 & 5658 \\
\hline
\end{tabular}

Notes: Table shows summary statistics for data aggregated at the port-year level. See main text for additional details on variable construction. 
Table A2: Robustness to restricting time period

\begin{tabular}{lcccccc}
\hline \multicolumn{7}{c}{ Dependent Variable: Slave Exports } \\
& $(1)$ & $(2)$ & $(3)$ & $(4)$ & $(5)$ & $(6)$ \\
& $1801-1810$ & $1811-1820$ & $1821-1830$ & $1831-1840$ & $1841-1850$ & $1851-1866$ \\
\hline Rain $_{t-1}$ & 80.9 & -201.1 & -334.9 & -203.1 & -123.2 & -213.1 \\
& $(187.5)$ & $(184.9)$ & $(208.2)$ & $(186.2)$ & $(213.0)$ & $(434.2)$ \\
Flood $_{t-1}$ & 815.1 & 1042.2 & 2063.7 & 393.4 & 1190.8 & 3513.0 \\
& $(859.7)$ & $(1186.8)$ & $(808.3)$ & $(1642.5)$ & $(1514.5)$ & $(1341.7)$ \\
Temp $_{t}$ & 53.8 & -149.5 & 800.2 & -8315.6 & -7510.1 & 10032.1 \\
& $(2207.7)$ & $(1311.8)$ & $(706.5)$ & $(4001.1)$ & $(1810.4)$ & $(7539.1)$ \\
\hline Port F.E. & Yes & Yes & Yes & Yes & Yes & Yes \\
Year F.E. & Yes & Yes & Yes & Yes & Yes & Yes \\
Obs. & 1107 & 1230 & 1230 & 1230 & 1230 & 1968 \\
\hline
\end{tabular}

Notes: Table shows the results of Tobit regressions with port and year fixed effects after restricting the sample to various time periods. Column (1) restricts the data to 1801-1810, Column (2) restricts to 1811-1820, Column (3) restricts to 1821-1830, Column (4) restricts to 1831-1840, Column (5) restricts to 1841-1850, and Column (6) restricts to 1851-1866. Standard errors clustered by rainfall region are in parentheses below. 
Table A3: Robustness to restricting sample

\begin{tabular}{lccccc}
\hline \multicolumn{5}{c}{ Dependent Variable: Slave Exports } \\
& $(1)$ & $(2)$ & $(3)$ & $(4)$ & $(5)$ \\
& W. Africa & W.C. Africa & E. Africa & No small ports & No large ports \\
\hline Rain $_{t-1}$ & -116.2 & -687.0 & 982.4 & -402.9 & -145.3 \\
& $(79.6)$ & $(167.8)$ & $(87.6)$ & $(96.9)$ & $(58.7)$ \\
Flood $_{t-1}$ & 484.1 & 2046.8 & -6271.8 & 230.3 & 742.3 \\
& $(402.1)$ & $(737.3)$ & $(598.3)$ & $(677.9)$ & $(439.6)$ \\
Temp $_{t}$ & -675.5 & -3961.3 & 6178.0 & -957.0 & -442.5 \\
& $(1091.2)$ & $(3576.3)$ & $(5227.4)$ & $(1847.1)$ & $(957.5)$ \\
\hline Port F.E. & Yes & Yes & Yes & Yes & Yes \\
Year F.E. & Yes & Yes & Yes & Yes & Yes \\
Obs. & 5720 & 1625 & 650 & 1365 & 7345 \\
\hline
\end{tabular}

Notes: Table shows the results of Tobit regressions with port and year fixed effects after making various sample restrictions. Dependent variable is the number of slaves exported from a port in a given year. Columns (1)-(3) restrict the data to ports in West Africa, West-Central Africa, and East Africa respectively as defined by Figure A8. Column (4) excludes ports which have no more than 22,000 slave exports during the 1801-1866 time period. Column (5) excludes ports which have no less than 100,000 slave exports during the 1801-1866 time period. Standard errors clustered by rainfall region are in parentheses below. 
Table A4: Robustness to alternative estimators

\begin{tabular}{|c|c|c|c|c|c|}
\hline \multicolumn{6}{|c|}{ Dependent Variable: Slave Exports } \\
\hline & $(1)$ & $(2)$ & $(3)$ & $(4)$ & $(5)$ \\
\hline & Wooldridge (2002) & OLS FE & $\log (1+$ Slave Exports $)$ & Logit FE & OLS FD \\
\hline $\operatorname{Rain}_{t-1}$ & $\begin{array}{r}-288.1 \\
(92.0)\end{array}$ & $\begin{array}{l}-185.0 \\
(39.0)\end{array}$ & $\begin{array}{l}-0.045 \\
(0.016)\end{array}$ & $\begin{array}{l}-0.117 \\
(0.039)\end{array}$ & $\begin{array}{r}-132.1 \\
(47.0)\end{array}$ \\
\hline Flood $_{t-1}$ & $\begin{array}{c}1643.4 \\
(1230.4)\end{array}$ & $\begin{array}{c}223.1 \\
(346.6)\end{array}$ & $\begin{array}{c}0.186 \\
(0.184)\end{array}$ & $\begin{array}{c}0.614 \\
(0.323)\end{array}$ & $\begin{array}{c}833.3 \\
(402.5)\end{array}$ \\
\hline $\operatorname{Temp}_{t}$ & $\begin{array}{c}-993.8 \\
(1298.1)\end{array}$ & $\begin{array}{l}-1773.9 \\
(1519.0)\end{array}$ & $\begin{array}{c}0.062 \\
(0.235)\end{array}$ & $\begin{array}{c}-0.193 \\
(0.473)\end{array}$ & $\begin{array}{r}-1247.9 \\
(379.4)\end{array}$ \\
\hline Port F.E. & No & Yes & Yes & Yes & No \\
\hline Year F.E. & Yes & Yes & Yes & Yes & Yes \\
\hline Obs. & 7995 & 1068 & 7995 & 5135 & 1036 \\
\hline
\end{tabular}

Notes: Table shows the relationship between climate and slave exports using various estimators. Unless otherwise specified, the dependent variable is the number of slaves exported from a port in a given year. Column (1) is a Tobit regression that follows Wooldridge $(2002,542)$ and replaces port fixed effects with port-specific average temperature and average rainfall level to avoid the incidental parameter issue in Tobit regressions. Column (2) is a two-way fixed effects OLS regression that restricts to port-years such that Slaves $_{i t}>0$. Column (3) is a two-way fixed effects OLS regression that uses $\log \left(1+\right.$ Slaves $\left._{i t}\right)$ as the dependent variable. Column (4) is a logit regression with conditional fixed-effects that uses an indicator for Slaves $i t>0$ as the dependent variable and uses the observed information matrix for standard errors. Column (5) is the same as Column (2) except that is estimated via first differences with year fixed effects. Standard errors clustered by rainfall region (unless otherwise specified) are in parentheses below. 
Table A5: Robustness to alternative estimators cont.

\begin{tabular}{|c|c|c|c|c|c|c|}
\hline \multicolumn{7}{|c|}{ Dependent Variable: Slave Exports } \\
\hline & $(1)$ & $(2)$ & $(3)$ & $(4)$ & $(5)$ & (6) \\
\hline & Normalized & No Flood & Bootstrap & Linear & Quadratic & $\begin{aligned} & \text { Quad. } \\
+ & \text { Year FE }\end{aligned}$ \\
\hline $\operatorname{Rain}_{t-1}$ & $\begin{array}{l}-437.1 \\
(129.3)\end{array}$ & $\begin{array}{l}-231.6 \\
(66.2)\end{array}$ & $\begin{array}{l}-280.3 \\
(75.8)\end{array}$ & $\begin{array}{l}-94.5 \\
(49.0)\end{array}$ & $\begin{array}{l}-94.0 \\
(49.3)\end{array}$ & $\begin{array}{l}-212.6 \\
(46.4)\end{array}$ \\
\hline Flood $_{t-1}$ & $\begin{array}{l}1151.4 \\
(630.8)\end{array}$ & - & $\begin{array}{l}1158.8 \\
(546.6)\end{array}$ & $\begin{array}{c}415.6 \\
(312.3)\end{array}$ & $\begin{array}{c}681.4 \\
(451.8)\end{array}$ & $\begin{array}{c}307.3 \\
(345.2)\end{array}$ \\
\hline $\operatorname{Temp}_{t}$ & $\begin{array}{c}49.9 \\
(194.3)\end{array}$ & $\begin{array}{l}-1481.5 \\
(1523.2)\end{array}$ & $\begin{array}{l}-1394.6 \\
(1024.6)\end{array}$ & $\begin{array}{l}-2096.7 \\
(1746.4)\end{array}$ & $\begin{array}{l}-2676.9 \\
(1920.3)\end{array}$ & $\begin{array}{l}-3680.8 \\
(1368.7)\end{array}$ \\
\hline Port F.E. & Yes & Yes & Yes & Yes & Yes & Yes \\
\hline Year F.E. & Yes & Yes & Yes & No & No & Yes \\
\hline Obs. & 7995 & 7995 & 7995 & 1068 & 1068 & 1068 \\
\hline
\end{tabular}

Notes: Table shows the results of Tobit and OLS regressions with various empirical specifications. Dependent variable is the number of slaves exported from a port in a given year. Column (1) is a Tobit regression that normalizes Rain $_{t-1}$ and $\mathrm{Temp}_{t}$ to have mean zero and unit standard deviation within a given port. Column (2) is a Tobit regression that drops Flood $_{t-1}$ from the specification. Column (3) is a Tobit regression that uses a nonparametric bootstrap at the port-year level with 50 replicates to construct standard errors. Column (4) is an OLS regression restricted to port-years such that Slaves $_{i t}>0$ and replaces year fixed effects with port-specific linear time trends. Column (5) is the same as Column (4) but also includes port-specific quadratic time trends. Column (5) is the same as Column (5) but also includes year fixed effects. Standard errors clustered by rainfall region (unless otherwise specified) are in parentheses below. 
Table A6: Robustness to measurement error

\begin{tabular}{|c|c|c|c|c|c|c|c|c|}
\hline \multicolumn{9}{|c|}{ Dependent Variable: Slave Exports } \\
\hline & (1) & $(2)$ & (3) & $(4)$ & $(5)$ & (6) & (7) & $(8)$ \\
\hline $\operatorname{Rain}_{t-1}$ & $\begin{array}{l}-247.1 \\
(94.3)\end{array}$ & $\begin{array}{l}-234.1 \\
(119.1)\end{array}$ & $\begin{array}{l}-228.4 \\
(209.0)\end{array}$ & $\begin{array}{c}-333.4 \\
(283.0)\end{array}$ & $\begin{array}{l}-706.6 \\
(415.4)\end{array}$ & $\begin{array}{c}-85.4 \\
(412.2)\end{array}$ & $\begin{array}{c}136.2 \\
(10953.9)\end{array}$ & $\begin{array}{l}-642.5 \\
(272.7)\end{array}$ \\
\hline Flood $_{t-1}$ & $\begin{array}{l}1112.9 \\
(684.9)\end{array}$ & $\begin{array}{l}1027.5 \\
(990.2)\end{array}$ & $\begin{array}{c}4990.2 \\
(3296.3)\end{array}$ & $\begin{array}{c}5567.8 \\
(3512.6)\end{array}$ & $\begin{array}{c}6772.1 \\
(2807.9)\end{array}$ & $\begin{array}{c}1080.6 \\
(1433.3)\end{array}$ & $\begin{array}{c}0.0 \\
(0.0)\end{array}$ & $\begin{array}{c}1915.5 \\
(2653.8)\end{array}$ \\
\hline $\mathrm{Temp}_{t}$ & $\begin{array}{l}-1953.7 \\
(1156.1)\end{array}$ & $\begin{array}{c}-570.7 \\
(1626.1)\end{array}$ & $\begin{array}{l}-3619.0 \\
(2550.7)\end{array}$ & $\begin{array}{l}-3482.1 \\
(3567.1)\end{array}$ & $\begin{array}{c}-7146.7 \\
(4802.2)\end{array}$ & $\begin{array}{r}-12096.4 \\
(5255.7)\end{array}$ & $\begin{array}{l}-4470.8 \\
(7399.6)\end{array}$ & $\begin{array}{l}-7000.5 \\
(4580.7)\end{array}$ \\
\hline Port F.E. & Yes & Yes & Yes & Yes & Yes & Yes & Yes & Yes \\
\hline Year F.E. & Yes & Yes & Yes & Yes & Yes & Yes & Yes & Yes \\
\hline Obs. & 5618 & 4995 & 2618 & 1863 & 1719 & 861 & 964 & 1393 \\
\hline
\end{tabular}

Notes: Table shows the results of Tobit regressions with various restrictions to the type of reconstructed rainfall data used. Dependent variable is the number of slaves exported from a port in a given year. Column (1) drops all observations created using regional substitution. Column (2) drops all observations created using spatial reconstruction. Column (3) drops all observations created using either regional substitution or spatial reconstruction. Column (4) drops all observations created using regional substitution, spatial reconstruction, or a single piece of non-gauge and non-lake-based documentary information. Column (5) drops all observations created using regional substitution, spatial reconstruction, or only non-gauge and non-lake-based documentary information. Column (6) uses the mean of all rainfall gauge available in a region for a given year. For Column (6), 87, 13, and 1 percent of observations come from West, West-Central, and East Africa respectively. Column (7) uses the mean of all lake-based documentary information available in a region for a given year. For Column (7), 98, 0, and 2 percent of observations come from West, West-Central, and East Africa respectively. Column (8) uses the mean of all non-gauge and non-lake-based documentary information available in a region for a given year. For Column (8), 70, 28, and 3 percent of observations come from West, West-Central, and East Africa respectively. The rainfall variable in Columns (6)-(8) is still demeaned by the port-specific mean using all available rainfall data. The flood variable in Columns (6)-(8) is an indicator for whether the demeaned gauge / lake / historical] rainfall variable is greater than three. Due to a small number of available rainfall regions, robust standard errors (which are roughly the same or more conservative across specifications than standard errors clustered by rainfall regions) are used. 
Table A7: Droughts and Conflict in 19th Century Africa - Region aggregated

\begin{tabular}{|c|c|c|c|c|c|c|c|c|c|}
\hline \multicolumn{10}{|c|}{ Dependent Variable: Indicator for Conflict } \\
\hline & \multicolumn{2}{|c|}{ Slave Regions } & \multicolumn{2}{|c|}{$\underline{\text { Non-slave Regions }}$} & & \multicolumn{2}{|c|}{ Slave Regions } & \multicolumn{2}{|c|}{$\underline{\text { Non-slave Regions }}$} \\
\hline & $(1)$ & $(2)$ & $(3)$ & $(4)$ & & $(5)$ & (6) & $(7)$ & $(8)$ \\
\hline $\operatorname{Rain}_{t-1}$ & $\begin{array}{l}-0.126 \\
(0.084)\end{array}$ & & $\begin{array}{c}0.030 \\
(0.042)\end{array}$ & & Rain $_{\text {Trend }}$ & $\begin{array}{c}-0.100 \\
(0.117)\end{array}$ & $\begin{array}{c}-0.142 \\
(0.121)\end{array}$ & $\begin{array}{c}0.053 \\
(0.064)\end{array}$ & $\begin{array}{c}0.038 \\
(0.069)\end{array}$ \\
\hline Flood $_{t-1}$ & $\begin{array}{c}0.990 \\
(0.510)\end{array}$ & & $\begin{array}{l}-0.271 \\
(0.322)\end{array}$ & & Rain Shock $_{t-1}$ & $\begin{array}{c}-0.047 \\
(0.083)\end{array}$ & & $\begin{array}{c}0.006 \\
(0.038)\end{array}$ & \\
\hline $\operatorname{Rain}_{t}$ & & $\begin{array}{l}-0.133 \\
(0.082)\end{array}$ & & $\begin{array}{l}-0.051 \\
(0.042)\end{array}$ & Rain Shock $_{t}$ & & $\begin{array}{c}-0.075 \\
(0.086)\end{array}$ & & $\begin{array}{l}-0.037 \\
(0.040)\end{array}$ \\
\hline Flood $_{t}$ & & $\begin{array}{c}1.318 \\
(0.560)\end{array}$ & & $\begin{array}{c}0.029 \\
(0.313)\end{array}$ & Temp Trend $_{t}$ & $\begin{array}{c}0.624 \\
(0.740)\end{array}$ & $\begin{array}{c}0.630 \\
(0.715)\end{array}$ & $\begin{array}{c}-0.189 \\
(0.389)\end{array}$ & $\begin{array}{l}-0.229 \\
(0.379)\end{array}$ \\
\hline $\operatorname{Temp}_{t}$ & $\begin{array}{c}-0.434 \\
(0.431) \\
\end{array}$ & $\begin{array}{c}-0.384 \\
(0.430) \\
\end{array}$ & $\begin{array}{c}-0.165 \\
(0.235) \\
\end{array}$ & $\begin{array}{c}-0.166 \\
(0.235) \\
\end{array}$ & Temp Shock $_{t}$ & $\begin{array}{c}-0.463 \\
(0.420) \\
\end{array}$ & $\begin{array}{c}-0.452 \\
(0.419) \\
\end{array}$ & $\begin{array}{c}-0.173 \\
(0.252) \\
\end{array}$ & $\begin{array}{c}-0.066 \\
(0.249) \\
\end{array}$ \\
\hline Region F.E. & Yes & Yes & Yes & Yes & & Yes & Yes & Yes & Yes \\
\hline Year F.E. & Yes & Yes & Yes & Yes & & Yes & Yes & Yes & Yes \\
\hline Obs. & 440 & 440 & 1083 & 1083 & & 432 & 440 & 954 & 972 \\
\hline
\end{tabular}

Notes: Probit regressions with region and year fixed effects and robust standard errors in parentheses. Dependent variable is an indicator for whether a conflict occurred within the homogenous rainfall region in a given year. 'Rain Trend ${ }_{t}$ ' is a 5-year moving average of the previous rainfall levels. 'Rain Shock $t_{t-1}$ ' is the deviation from the 5-year moving average in the previous year. 'Temp Trend ${ }_{t}$ ' and 'Temp Shock ${ }_{t}$ ' are defined analogously. Data on conflicts in columns (1), (2), (5), and (6) is restricted to regions with slave ports from the main sample. Data on conflicts in columns (3), (4), (7), and (8) is restricted to regions without slave ports from the main sample. Coefficients are reported. 
Figure A1: Rainfall Anomalies by Region
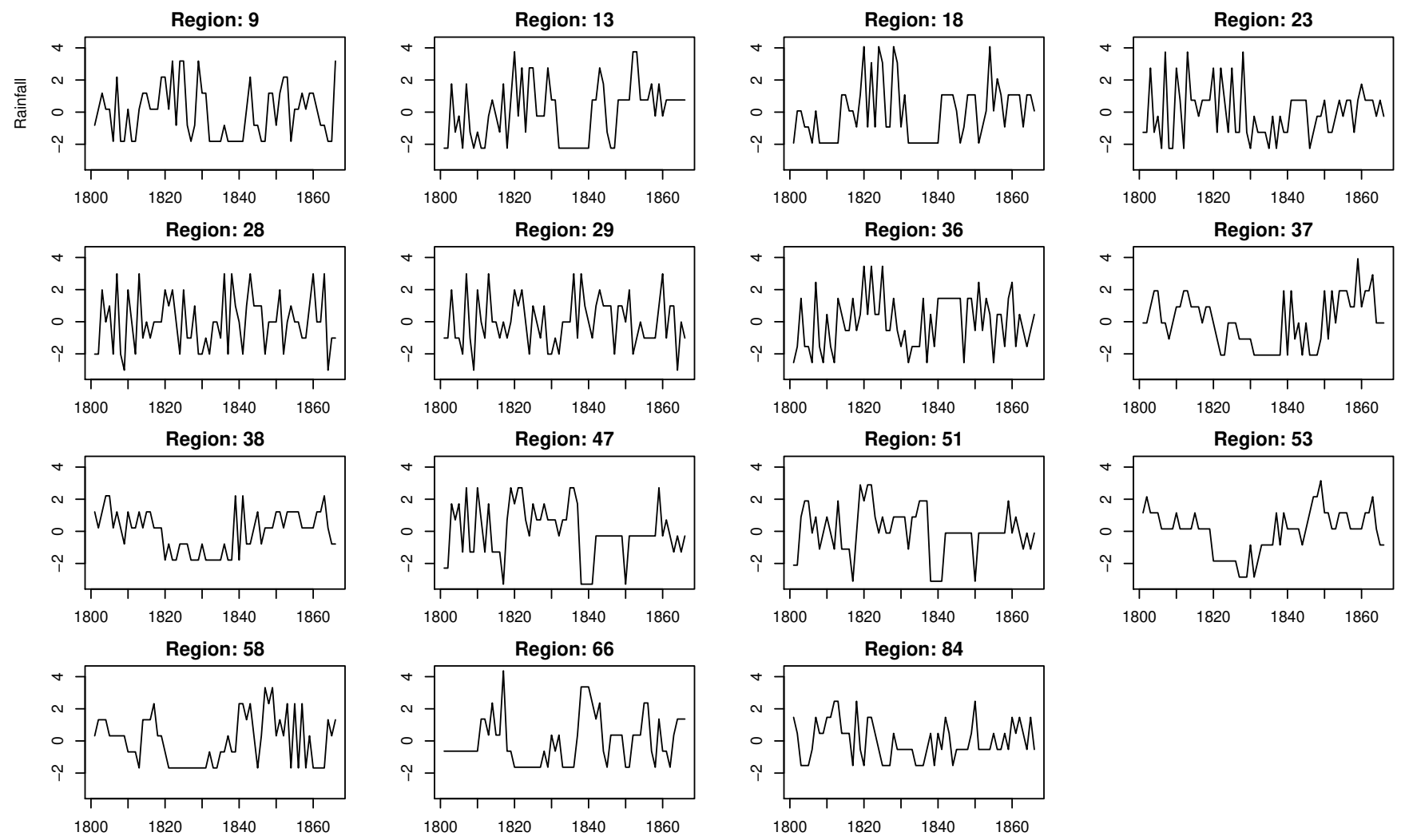

Notes: Plot shows the demeaned rainfall value for each rainfall region in the main sample. Rainfall region ids can be found in Figure A8. 
Figure A2: Temperature Anomalies by Region
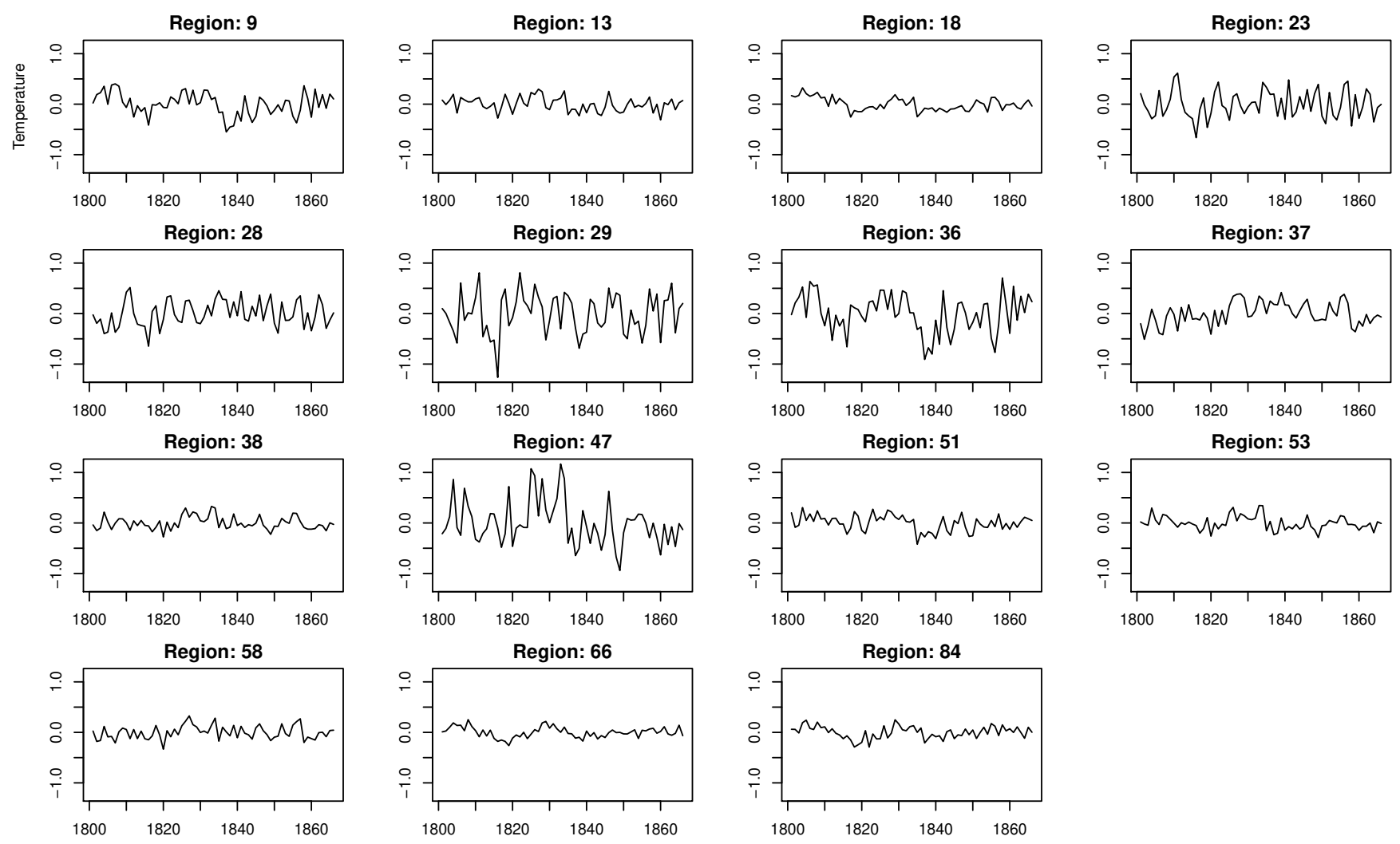

Notes: Plot shows the demeaned temperature for each rainfall region in the main sample. Rainfall region ids can be found in Figure A8. 
Figure A3: Little Ice Age

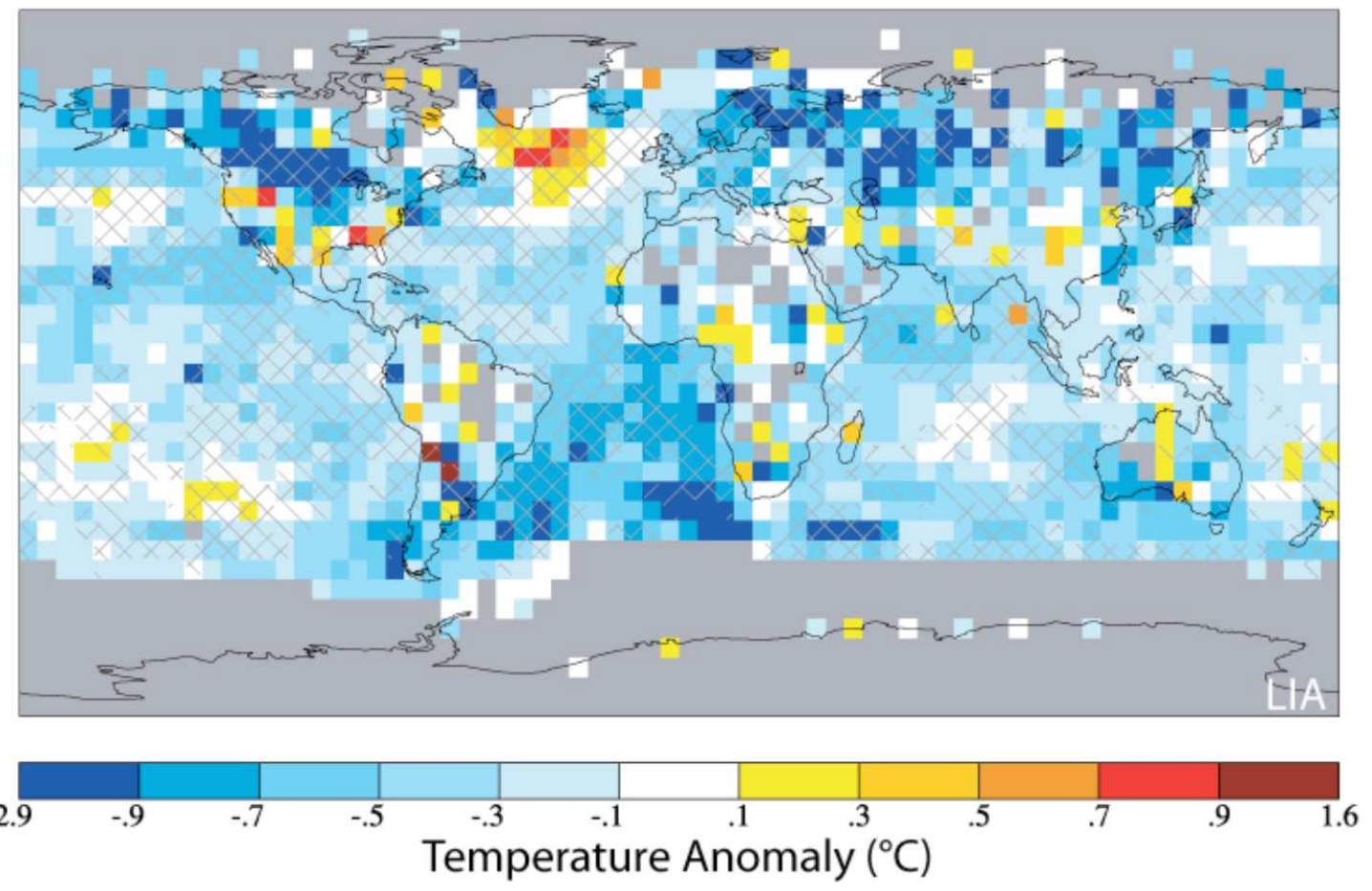

Notes: Figure shows the average temperature anomaly across the 1600-1850 time period. From

Mann, Michael E., Zhihua Zhang, Scott Rutherford, Raymond S. Bradley, Malcolm K. Hughes, Drew Shindell, Caspar Ammann, Greg Faluvegi, and Fenbiao Ni. 2009. "Global Signatures and Dynamical Origins of the Little Ice Age and Medieval Climate Anomaly." Science, 326(5957): 1256-1260.

Reprinted with permission from AAAS. Figure is the bottom panel of S9 from the SI. 


\section{Figure A4: Average Temperature Anomaly at Ports}

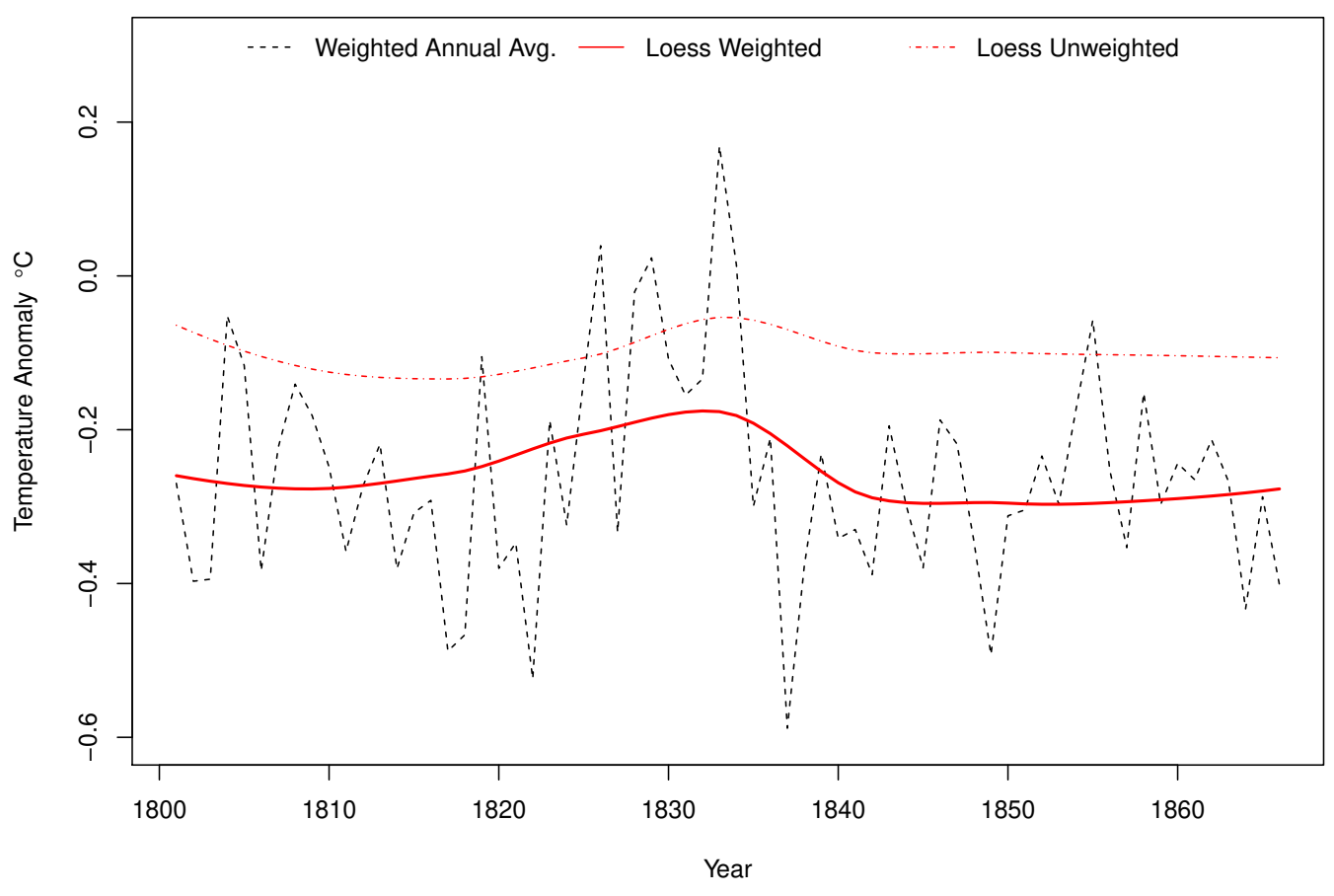

Notes: Figure shows the average temperature anomaly across the 1801-1866 time period for each port. The 'Weighted Annual Avg.' series is the weighted average temperature anomaly (before demeaning) across ports in the sample using the total number of slave exported from a given port across 1801-1866 time period as the weights. 'Loess Weighted' is a the fitted values from a loess regression using the 'Weighted Annual Avg.' series. 'Loess Unweighted' is a loess regression using the unweighted average temperature anomaly across ports in the sample. 
Figure A5: Slave Exports by Region
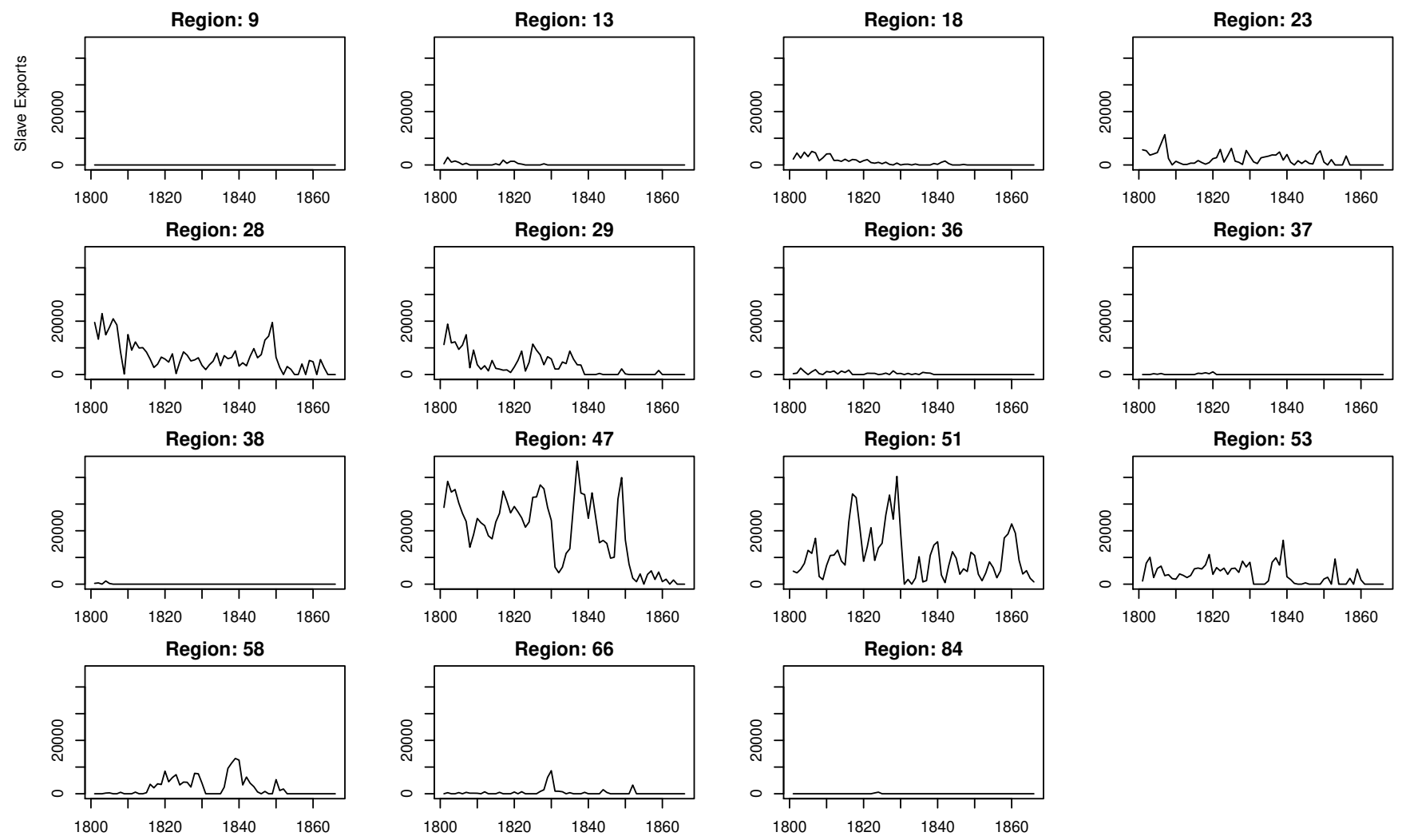

Notes: Plot shows the number of slave exports per year for each rainfall region in the main sample. Rainfall region ids can be found in Figure A8. 
Figure A6: Total Annual Slave Exports

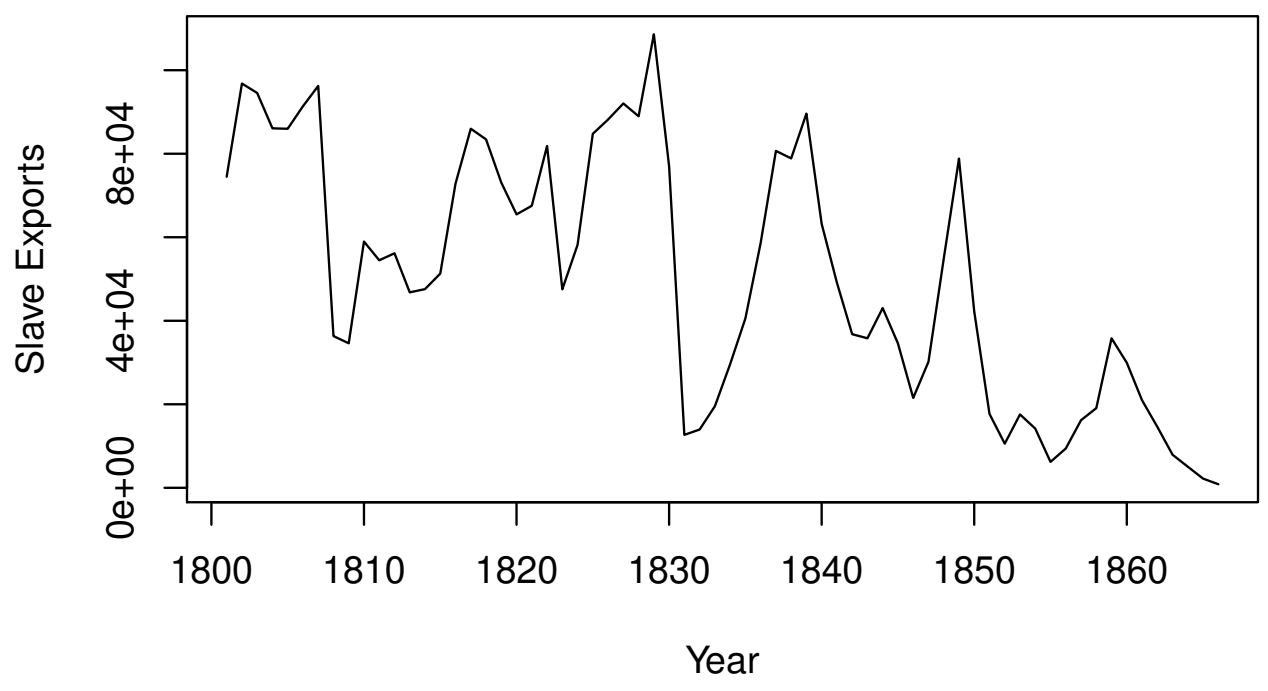

Notes: Plot shows the total number of slave exports for each year from 1801 to 1866 from the main sample of ports. 
Figure A7: Total Annual Slave Exports by Regional Division

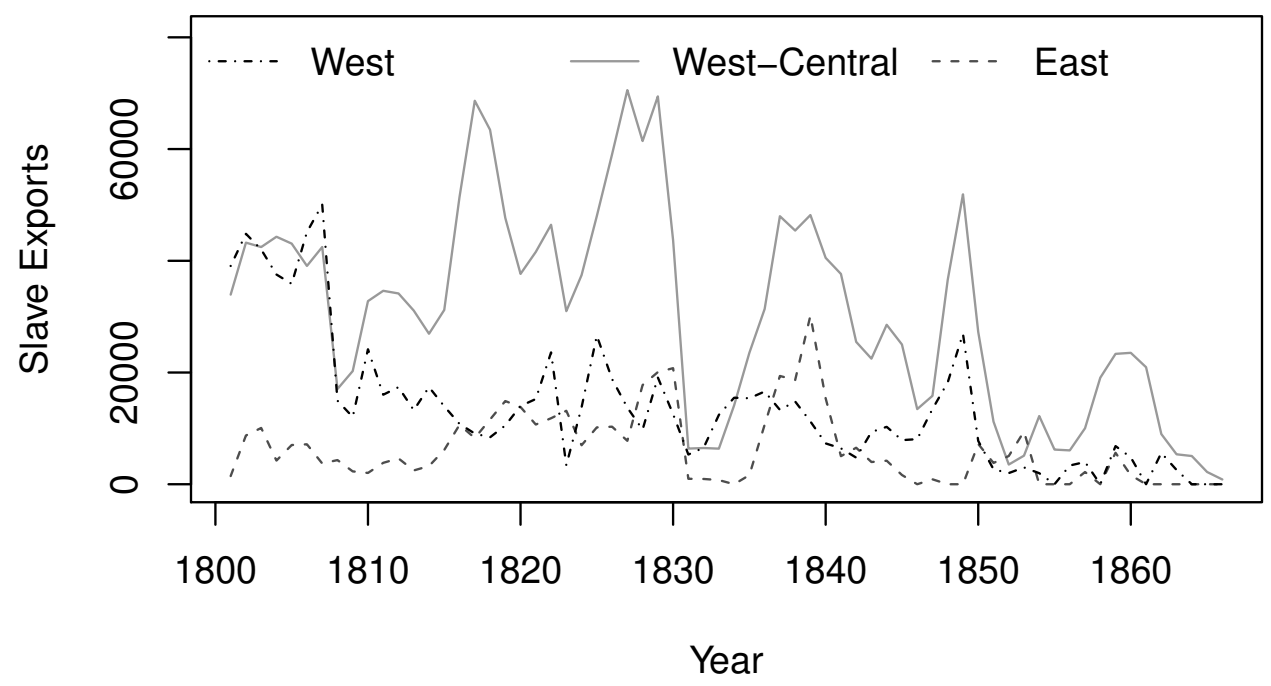

Notes: Plot shows, separately for West, West-Central, East Africa, the total number of slave exports for each year from 1801 to 1866 from the main sample of ports. Regional divisions can be found in Figure A8. 
Figure A8: Regional Division

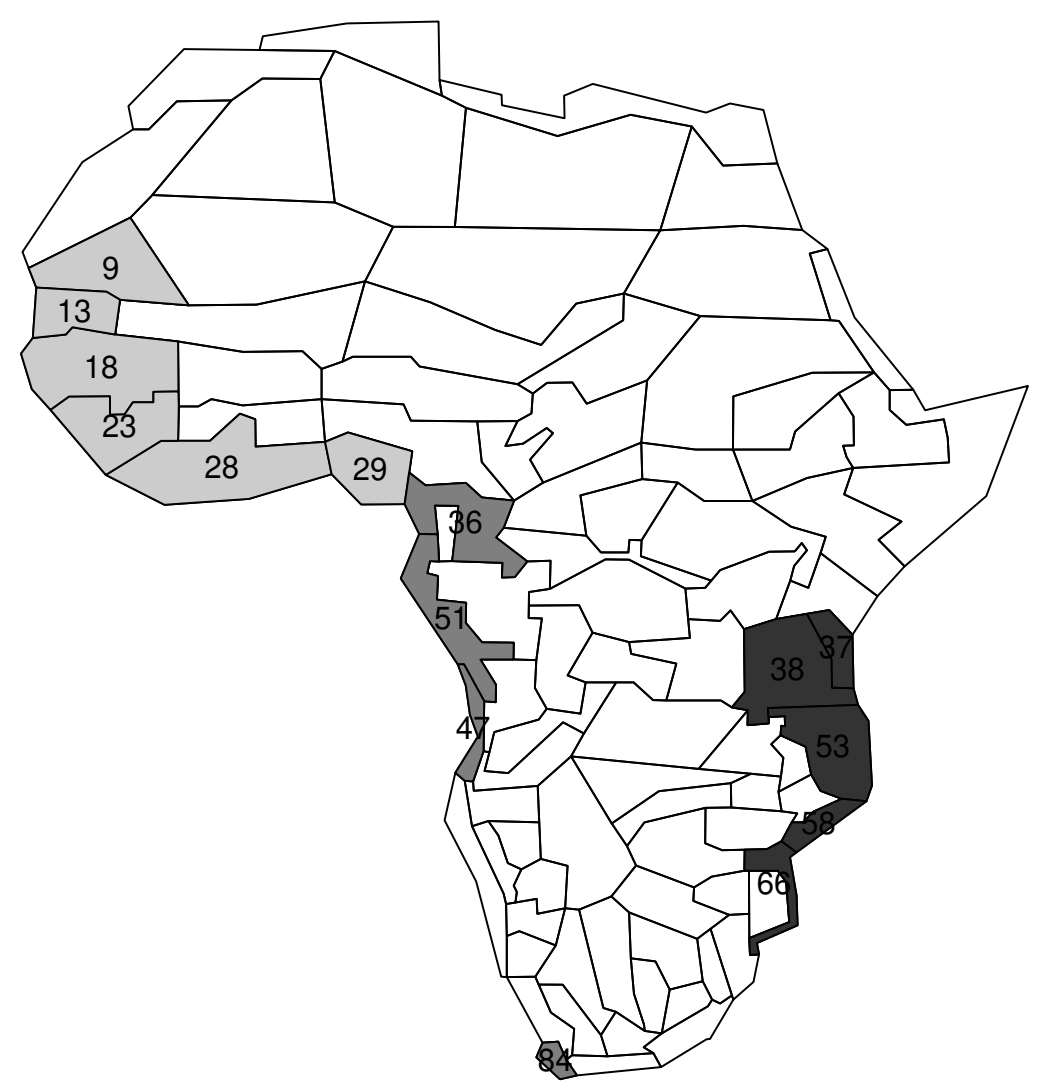

Notes: The light grey regions are denoted as West Africa, medium grey regions are denoted as West-Central Africa, and the dark grey regions are denoted as East Africa. Rainfall regions come from Nicholson (2001). Each rainfall region with slave exporting ports is numbered with its unique id from Nicholson (2001). 
Figure A9: Lag Testing
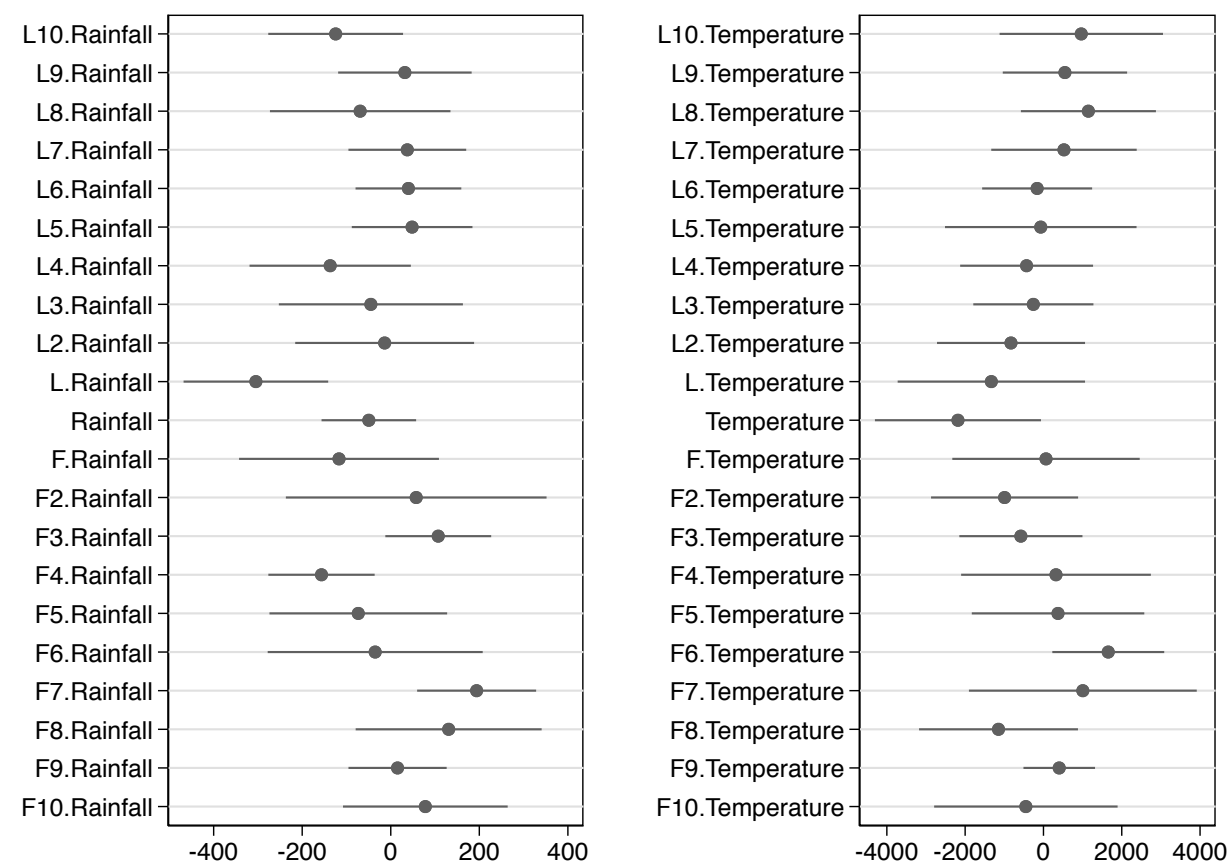

Notes: Figure shows the coefficients along with standard errors clustered by homogeneous rainfall region from two separate Tobit regressions - one with various lagged and future values of rainfall and one with various lagged and future values of temperature. Both regressions use slave exports as their dependent variable and include year and port fixed effects. The rainfall regression also includes the flood indicator variable that corresponds to each rainfall variable. Note that ' $L$ ' denotes 'lag' and 'F' denotes 'forward'. 
Figure A10: Conflict locations

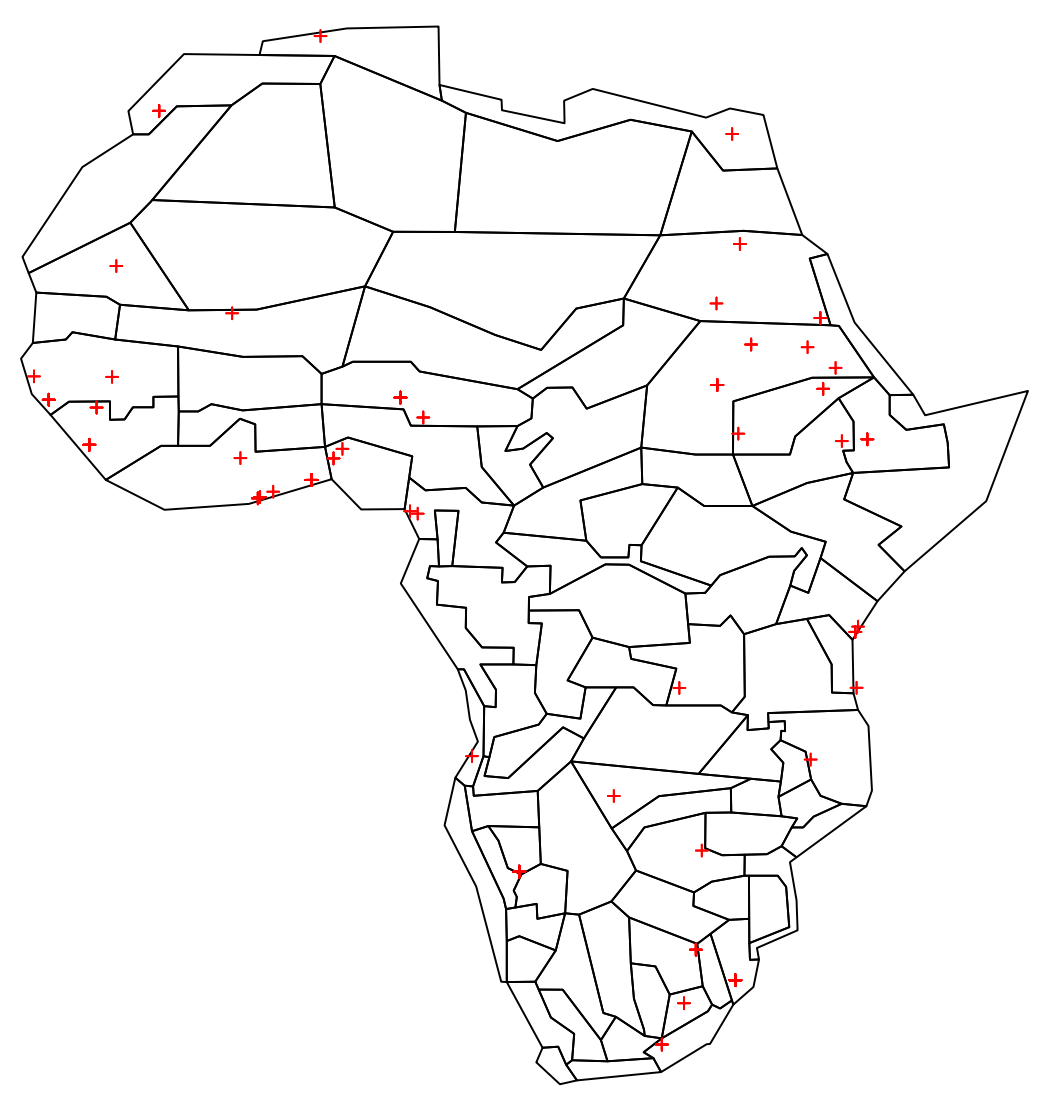

Notes: Rainfall regions come from Nicholson (2001). Conflict locations are taken from Fenske and Kala (2017). Red crosses show unique locations of conflicts between 1801 and 1866, which may persist or occur across multiple years. 


\section{Appendix: B (Online Appendix)}

\subsection{Economic Model}

To explain the relationship between climate shocks and slave exports, I develop a model within the spirit of Fenske and Kala (2015). However, I deviate by incorporating rainfall shocks and allowing for the opportunity cost of participating in the slave trade.

Consider an individual (possibly a coastal ruler, representative agent, or head of household) who must choose the degree of specialization between the slave trade and agriculture to maximize economic profit. The individual is faced with the following maximization problem:

$$
\underset{S \geq 0}{\operatorname{argmax}} P(S) S-C(S, T, R)-F(S, T, R)
$$

where $P(S)$ is the price for selling $S$ slaves, $C(S, T, R)$ is the explicit cost of acquiring and selling $S$ slaves given rainfall $R$ and temperature $T$ conditions, and $F(S, T, R)$ is the opportunity cost of acquiring and selling $S$ slaves given rainfall $R$ and temperature $T$ conditions. Here, $S$ effectively operates as the degree of specialization into the slave trade. I assume $C$ and $F$ are increasing and strictly convex in $S$.

Using the first order conditions and the implicit function theorem, we can obtain the follow partial derivatives:

$$
\frac{\partial S}{\partial R}=\frac{C_{S R}+F_{S R}}{P_{S S} S+2 P_{S}-C_{S S}-F_{S S}}
$$

and

$$
\frac{\partial S}{\partial T}=\frac{C_{S T}+F_{S T}}{P_{S S} S+2 P_{S}-C_{S S}-F_{S S}} .
$$

I let

$$
P_{S S} S+2 P_{S}-C_{S S}-F_{S S}<0
$$

which will occur as long as both the degree of convexity in the demand curve faced by the individual and the degree of specialization into the slave trade are relatively small. It was rare for an individual to hold a monopoly on any aspect of the slave trade. ${ }^{19}$ Even if an

\footnotetext{
${ }^{19}$ For example, in Old Calabar, slave ships frequently bought from multiple, sometimes more than ten, slave traders in a single voyage (Behrendt, Latham and Northrup, 2010).
} 
individual happened to be a coastal ruler with a monopoly on the slave trade at a given port, he would face competition from the other slave exporting ports. The inter- and intra-port competition imply the individuals are probably price takers, which means the assumption in equation (4) is likely valid.

My empirical estimates suggest that $\frac{\partial S}{\partial R}<0$ and $\frac{\partial S}{\partial T}<0$. The negative estimates, along with the assumption that the denominator is negative, imply that $F_{S R}+C_{S R}>0$ and $F_{S T}+C_{S T}>0$. However, without further knowledge on the signs of $F_{S T}, F_{S R}, C_{S T}$, and $C_{S R}$, the primary mechanisms (explicit $C$ or opportunity $F$ costs) through which rainfall and temperature impact the slave trade are ambiguous.

A priori knowledge suggests positive rainfall shocks and negative temperature shocks tend to increase both farm revenues and agricultural production in contemporary Africa (Kurukulasuriya and Mendelsohn, 2008; Barrios, Ouattara and Strobl, 2008). However, evidence suggests that Africa may have been in a Little Ice Age during the early part of the 19th century (Nicholson et al., 2013), in which case, we'd expect negative temperature shocks to actually decrease agricultural production. Increased agricultural yields increase the opportunity costs of participating in the slave trade. Climate shocks also lead to income shocks. During a severe drought, the opportunity costs of not increasing participation in the slave trade may be starvation. In the absence of other methods to smooth consumption over prolonged periods, individuals may be forced to specialize to the point of self-selecting themselves, their friends, or their family members into the slave trade to prevent starvation. Other forms of specialization and consumption smoothing include kidnapping (Sparks, 2014, 135-138), the sale of pawned Africans into the slave trade (Lovejoy, 2012, 13), and conflict (Lovejoy, 2012, 85). Therefore, I let $F_{S T}>0$ and $F_{S R}>0$.

We can do a similar exercise for $C$, however, the sign is more ambiguous. $C_{S T}$ could be positive because higher temperatures increase the costs associated with the procurement of an additional slave through mechanisms such as the disease burden and heat exhaustion. However, during this time period, higher temperatures likely increased agricultural yields which would decrease the cost of feeding a slave raiding army, which would cause $C_{S T}$ to be negative. The sign of $C_{S R}$ is similarly unclear with competing mechanisms between the disease burden and agricultural-induced changes in explicit costs, such as feeding a slave raiding army. Droughts made Africans weak and more susceptible to European diseases, (Dias, 1981). On the other hand, the prevalence of cholera and malaria both increase with 
increased precipitation (Reyburn et al., 2011; Zhou et al., 2004). Anecdotal evidence suggests that while Africans primarily suffered from European diseases during periods of drought, Europeans primarily suffered from African diseases during periods of increased rainfall (Miller, 1982). Thus, while the African disease burden would suggest $C_{S R}>0$, the European disease burden and agricultural costs would suggest $C_{S R}<0$.

Since both $F_{S R}$ and $F_{S T}$ are likely positive, while $C_{R T}$ and $C_{S T}$ are only positive due to the disease burden, heat exhaustion, or related phenomenon, the model suggests that the negative relationship between the climate variables and slave exports is primarily driven by the opportunity costs of participating in the slave trade relative to agriculture.

\subsection{Port Sample}

I exclude eleven ports for being roughly greater than $30 \mathrm{~km}$ from the coast (as defined by the geo-referenced rainfall region map): Ambona, Cape Verde Islands, Fernando Po, Golf Of Guinea Islands, Madagascar, Madeira, Mascarene Islands, Mauritius (Ile De France), Princes Island, St. Lawrence, and Sao Tome. Ports not on the mainland, but within roughly $30 \mathrm{~km}$ of the coast are assigned the rainfall value for the region which they are closest to. Fernando Po is the closest port to the mainland that is excluded.

There are also 44 ports in the sample with no slave exports recorded after 1800: Alampo, Albreda, Andony, Apammin, Apollonia, Ardra, Arguim, Axim, Banana Islands, Boary, Cacandia, Cess, Danish Gold Coast, Dembia, Drouin, Epe, Grand Bassam, Grand Junk, Grand Popo, Iles Plantain, Joal (Or Saloum River), Lay, Legas, Little Junk, Liverpool River, Mano, Mpinda, Petit Mesurado, Portudal, Quaqua, Rio Assini, Rio Forcados, Rio Grande, River Del Rey, River Kissey, Sassandra, Scarcies, Sestos (Grand And Rock), Settra Kou, Soyo, St. Paul, Sugary, Tabou, and Wiamba.

Most of the ports with no exports after 1800 had little to no exports before this period. There are two main exceptions: Epe and Danish Gold Coast. These two ports had 76,479 and 15,949 slaves exported respectively from 1730 to 1800. Both Epe and Danish Gold Coast are in West Africa which dominated the slave trade until the slave trade shifted south after 1807. The average number of slaves exported over the entire 1730 to 1800 period for these ports, excluding Epe and Danish Gold Coast, is 1187. 


\subsection{Region Aggregated Results}

\subsubsection{Region Data Build}

The rainfall variable used for each region is the rainfall level after subtracting the regionspecific mean rainfall level. To assign a temperature value for each region, I create Voronoi polygons from the non-missing point data as shown in Figure B1. I then rasterize the Voronoi polygons using the temperature anomalies into a $100 \times 100$ grid of Africa and take the mean value for the pixels located in each homogeneous rainfall region for a given year. I then subtract the region-specific mean anomaly.

The number of slaves exported from each homogeneous rainfall region is then the sum of the slaves exported from each port located within the region. This results in 15 homogeneous rainfall regions. The average region in the sample exported over 3,300 slaves annually, as shown in Table B1. 
Table B1: Summary Statistics

\begin{tabular}{lccccc}
\hline Variable & Mean & Std. Dev. & Min. & Max. & Obs. \\
\hline Slave Exports & 3363.3 & 6985.9 & 0.0 & 46042.2 & 990 \\
Rainfall (demeaned) & 0.000 & 1.532 & -3.288 & 4.364 & 990 \\
Weighted Rainfall & -0.005 & 0.085 & -2.638 & 0.070 & 990 \\
Flood Indicator & 0.029 & 0.169 & 0.000 & 1.000 & 990 \\
Weighted Flood & 0.002 & 0.009 & 0.000 & 0.171 & 990 \\
Temperature (demeaned) & -0.000 & 0.241 & -1.264 & 1.168 & 990 \\
Weighted Temperature & -0.000 & 0.005 & -0.154 & 0.011 & 990 \\
5-Year MA Rainfall & 0.008 & 0.967 & -2.688 & 2.764 & 915 \\
5-Year MA Temperature & -0.001 & 0.141 & -0.625 & 0.656 & 915 \\
Deviation from Rainfall's 5-Year MA & -0.008 & 1.571 & -5.000 & 4.600 & 915 \\
Deviation from Temperature's 5-Year MA & -0.001 & 0.253 & -1.069 & 1.231 & 915 \\
10-Year MA Rainfall & -0.008 & 0.790 & -2.148 & 1.924 & 840 \\
10-Year MA Temperature & -0.002 & 0.104 & -0.414 & 0.605 & 840 \\
Deviation from Rainfall's 10-Year MA & 0.028 & 1.561 & -4.500 & 4.600 & 840 \\
Deviation from Temperature's 10-Year MA & -0.008 & 0.257 & -1.246 & 1.143 & 840 \\
20-Year MA Rainfall & -0.051 & 0.549 & -1.498 & 1.312 & 690 \\
20-Year MA Temperature & -0.002 & 0.071 & -0.252 & 0.269 & 690 \\
Deviation from Rainfall's 20-Year MA & 0.011 & 1.653 & -4.600 & 4.650 & 690 \\
Deviation from Temperature's 20-Year MA & 0.009 & 0.249 & -1.028 & 1.110 & 690 \\
\hline
\end{tabular}

Notes: Table shows summary statistics for data aggregated at the region-year level. See text in Appendix $\mathrm{B}$ for additional details on variable construction. 
Table B2: Main Results

Dependent Variable: Slave Exports

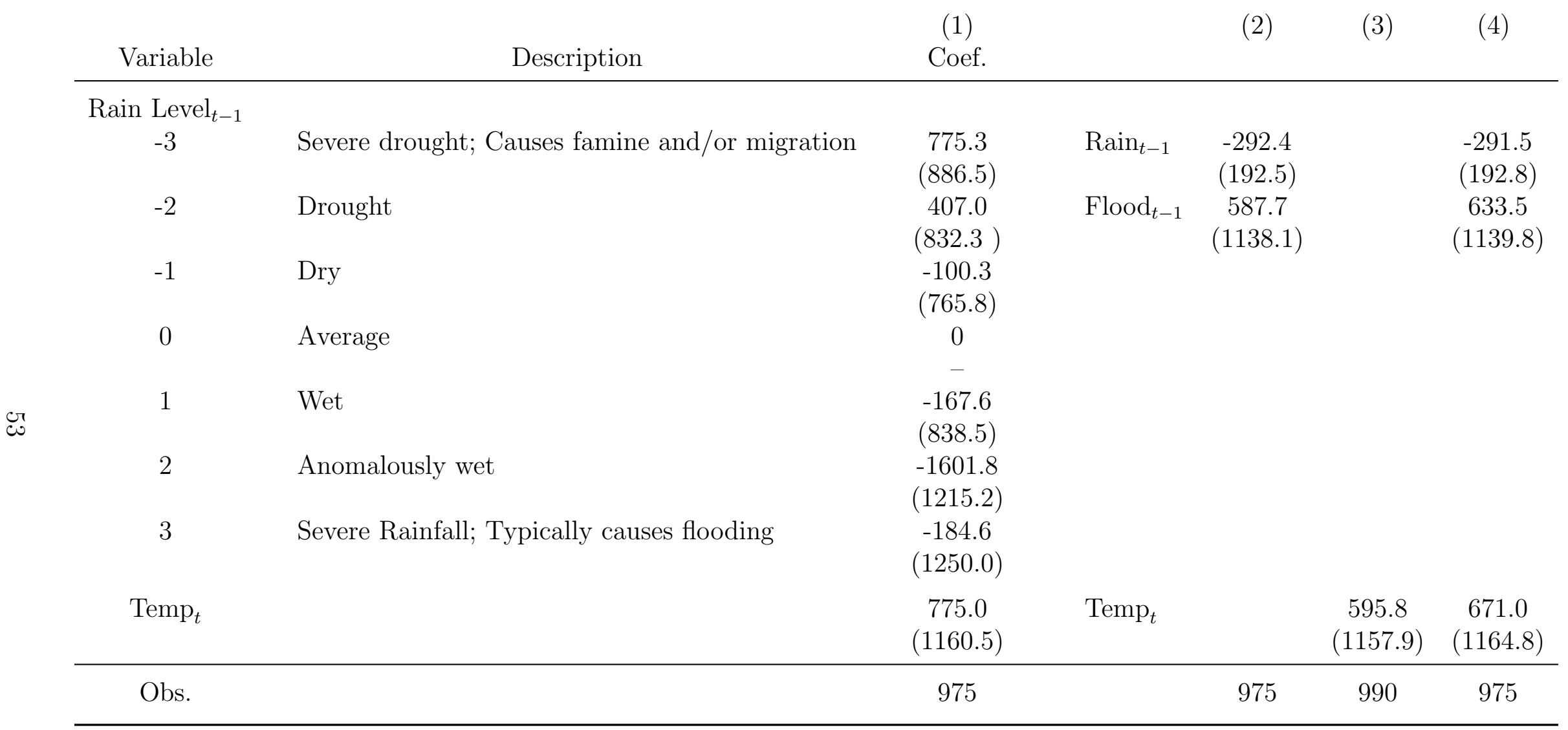

Notes: Table shows Tobit regressions with year and rainfall region fixed effects. Dependent variable is the number of slaves exported from a region in a given year. Column (1) uses indicators for the individual rainfall levels, while Columns (2) and (4) use the demeaned rainfall variable and an indicator for whether the demeaned rainfall variable is greater than three. Temp $t_{t}$ is the demeaned temperature in the rainfall region. Robust standard errors are in parentheses. 
Table B3: Trends and Shocks

\begin{tabular}{|c|c|c|c|c|c|c|}
\hline \multicolumn{7}{|c|}{ Dependent Variable: Slave Exports } \\
\hline & \multicolumn{2}{|c|}{$\underline{5 \text { Year MA }}$} & \multicolumn{2}{|c|}{10 Year MA } & \multicolumn{2}{|c|}{$\underline{20 \text { Year MA }}$} \\
\hline & (1) & $(2)$ & $(3)$ & $(4)$ & $(5)$ & $(6)$ \\
\hline Rain Trend $_{t}$ & $\begin{array}{l}-301.7 \\
(261.7)\end{array}$ & $\begin{array}{l}-323.1 \\
(259.0)\end{array}$ & $\begin{array}{l}-524.9 \\
(390.8)\end{array}$ & $\begin{array}{l}-546.2 \\
(396.1)\end{array}$ & $\begin{array}{c}-543.4 \\
(713.5)\end{array}$ & $\begin{array}{c}-799.5 \\
(790.4)\end{array}$ \\
\hline Rain Shock $_{t-1}$ & & $\begin{array}{c}-418.9 \\
(160.0)\end{array}$ & & $\begin{array}{c}-250.8 \\
(170.5)\end{array}$ & & $\begin{array}{c}-333.9 \\
(189.4)\end{array}$ \\
\hline Temp $\operatorname{Trend}_{t}$ & $\begin{array}{c}7512.3 \\
(2012.1)\end{array}$ & $\begin{array}{c}9029.1 \\
(2377.3)\end{array}$ & $\begin{array}{l}16383.0 \\
(3554.2)\end{array}$ & $\begin{array}{l}17196.0 \\
(4064.7)\end{array}$ & $\begin{array}{l}31513.5 \\
(5729.7)\end{array}$ & $\begin{array}{l}35759.2 \\
(6626.9)\end{array}$ \\
\hline Temp Shock ${ }_{t}$ & & $\begin{array}{c}86.6 \\
(1352.6)\end{array}$ & & $\begin{array}{c}599.4 \\
(1578.1)\end{array}$ & & $\begin{array}{c}1809.6 \\
(2073.1)\end{array}$ \\
\hline Region F.E. & Yes & Yes & Yes & Yes & Yes & Yes \\
\hline Year F.E. & Yes & Yes & Yes & Yes & Yes & Yes \\
\hline Obs. & 915 & 900 & 840 & 825 & 690 & 675 \\
\hline
\end{tabular}

Notes: Tobit regressions with port and year fixed effects and robust standard errors in parentheses. Unless otherwise specified, the dependent variable is the number of slaves exported from a region in a given year. 'Rain Trend ${ }_{t}$ ' is a moving average of the previous rainfall levels. 'Rain Shock $_{t-1}$ ' is the deviation from the moving average in the previous year. 
Table B4: Robustness to restricting time period

\begin{tabular}{lcccccc}
\hline \multicolumn{7}{c}{ Dependent Variable: Slave Exports } \\
& $(1)$ & $(2)$ & $(3)$ & $(4)$ & $(5)$ & $(6)$ \\
& $1801-1810$ & $1811-1820$ & $1821-1830$ & $1831-1840$ & $1841-1850$ & $1851-1866$ \\
\hline Rain $_{t-1}$ & -73.8 & -614.0 & -842.2 & -377.3 & -540.3 & -82.5 \\
& $(427.6)$ & $(385.0)$ & $(330.8)$ & $(453.5)$ & $(529.5)$ & $(542.2)$ \\
Flood $_{t-1}$ & 1948.8 & 1318.3 & 4662.4 & -4382.7 & 1877.1 & -1041.9 \\
& $(2251.9)$ & $(2411.3)$ & $(1316.7)$ & $(3934.1)$ & $(3139.4)$ & $(2678.9)$ \\
Temp $_{t}$ & 134.6 & -1015.7 & 4406.1 & -4888.6 & -7491.2 & 5933.6 \\
& $(1779.2)$ & $(1172.6)$ & $(1330.2)$ & $(3345.0)$ & $(3227.0)$ & $(2901.5)$ \\
\hline Region F.E. & Yes & Yes & Yes & Yes & Yes & Yes \\
Year F.E. & Yes & Yes & Yes & Yes & Yes & Yes \\
Obs. & 135 & 150 & 150 & 150 & 150 & 240 \\
\hline
\end{tabular}

Notes: Table shows the results of Tobit regressions with region and year fixed effects after restricting the sample to various time periods. Column (1) restricts the data to 1801-1810, Column (2) restricts to 1811-1820, Column (3) restricts to 1821-1830, Column (4) restricts to 1831-1840, Column (5) restricts to 1841-1850, and Column (6) restricts to 1851-1866. Robust standard errors are in parentheses below. 
Table B5: Robustness to restricting sample

Dependent Variable: Slave Exports

(1)

(2)

(3)

(4)

(5)

W. Africa W.C. Africa E. Africa No small regions No large regions

\begin{tabular}{lccccc}
\hline Rain $_{t-1}$ & -243.8 & -1119.3 & 961.8 & -455.0 & -52.0 \\
& $(198.3)$ & $(574.9)$ & $(325.2)$ & $(229.6)$ & $(90.0)$ \\
Flood $_{t-1}$ & 1075.8 & 1756.7 & -6949.1 & 177.0 & -216.1 \\
& $(992.5)$ & $(3077.7)$ & $(2138.1)$ & $(1471.9)$ & $(681.4)$ \\
Temp $_{t}$ & 264.7 & 466.5 & 2264.4 & 826.8 & 75.4 \\
& $(855.7)$ & $(2239.1)$ & $(2370.5)$ & $(1410.7)$ & $(483.8)$ \\
\hline Region F.E. & Yes & Yes & Yes & Yes & Yes \\
Year F.E. & Yes & Yes & Yes & Yes & Yes \\
Obs. & 390 & 260 & 325 & 585 & 520 \\
\hline
\end{tabular}

Notes: Table shows the results of Tobit regressions with region and year fixed effects after making various sample restrictions. Dependent variable is the number of slaves exported from a region in a given year. Columns (1)-(3) restrict the data to regions in West Africa, West-Central Africa, and East Africa respectively as defined by Figure A8. Column (4) excludes regions which have no more than 22,000 slave exports during the 1801-1866 time period. Column (5) excludes regions which have no less than 100,000 slave exports during the 1801-1866 time period. Robust standard errors are in parentheses below. 
Table B6: Robustness to alternative estimators

\begin{tabular}{lccccc}
\hline \multicolumn{5}{c}{ Dependent Variable: Slave Exports } & \\
& $(1)$ & $(2)$ & $(3)$ & $(4)$ & $(5)$ \\
& Wooldridge $(2002)$ & OLS FE & $\log (1+$ Slave Exports $)$ & Logit FE & OLS FD \\
\hline Rain $_{t-1}$ & -293.7 & -245.7 & -0.080 & -0.032 & -412.8 \\
& $(295.4)$ & $(225.0)$ & $(0.063)$ & $(0.104)$ & $(141.7)$ \\
Flood $_{t-1}$ & 2188.9 & -324.5 & 0.687 & 0.852 & 2007.9 \\
& $(1846.5)$ & $(1321.5)$ & $(0.523)$ & $(0.812)$ & $(969.3)$ \\
Temp $_{t}$ & 1469.0 & -603.9 & 0.914 & 1.227 & -1318.7 \\
& $(1754.2)$ & $(1325.4)$ & $(0.354)$ & $(0.611)$ & $(797.1)$ \\
\hline Region F.E. & No & Yes & Yes & Yes & No \\
Year F.E. & Yes & Yes & Yes & Yes & Yes \\
Obs. & 975 & 462 & 975 & 910 & 451 \\
\hline
\end{tabular}

Notes: Table shows the relationship between climate and slave exports using various estimators. Unless otherwise specified, the dependent variable is the number of slaves exported from a region in a given year. Column (1) is a Tobit regression that follows Wooldridge $(2002,542)$ and replaces region fixed effects with port-specific average temperature and average rainfall level to avoid the incidental parameter issue in Tobit regressions. Column (2) is a two-way fixed effects OLS regression that restricts to region-years such that Slaves $i t>0$. Column (3) is a two-way fixed effects OLS regression that uses $\log \left(1+\right.$ Slaves $\left._{i t}\right)$ as the dependent variable. Column (4) is a logit regression with conditional fixed-effects that uses an indicator for Slaves $s_{i t}>0$ as the dependent variable and uses the observed information matrix for standard errors. Column (5) is the same as Column (2) except that is estimated via first differences with year fixed effects. Robust standard errors (unless otherwise specified) are in parentheses below. 
Table B7: Robustness to alternative estimators cont.

\begin{tabular}{lcccccc}
\hline \multicolumn{5}{c}{ Dependent Variable: Slave Exports } & & \\
& $(1)$ & $(2)$ & $(3)$ & $(4)$ & $(5)$ & $(6)$ \\
& Normalized & No Flood & Bootstrap & Linear & Quadratic & $\begin{array}{c}\text { Quad. } \\
\text { Year FE }\end{array}$ \\
\hline Rain $_{t-1}$ & & & & & & -372.2 \\
& $(296.9)$ & $(164.9)$ & $(196.5)$ & $(212.0)$ & $(206.7)$ & $(234.5)$ \\
Flood $_{t-1}$ & 610.1 & - & 633.5 & 582.3 & 903.2 & -683.9 \\
& $(1136.9)$ & - & $(1341.3)$ & $(936.1)$ & $(894.2)$ & $(1267.6)$ \\
Temp $_{t}$ & 428.6 & 654.4 & 671.0 & -1645.5 & -1789.2 & -1934.7 \\
& $(259.8)$ & $(1162.2)$ & $(1196.0)$ & $(1381.4)$ & $(1400.6)$ & $(1405.4)$ \\
\hline Region F.E. & Yes & Yes & Yes & Yes & Yes & Yes \\
Year F.E. & Yes & Yes & Yes & No & No & Yes \\
Obs. & 975 & 975 & 975 & 462 & 462 & 462 \\
\hline Not. Tables & & & & -291.5 & -301.8 & -286.7 \\
\hline
\end{tabular}

Notes: Table shows the results of Tobit and OLS regressions with various empirical specifications. Dependent variable is the number of slaves exported from a region in a given year. Column (1) is a Tobit regression that normalizes Rain R $_{t-1}$ and $\mathrm{Temp}_{t}$ to have mean zero and unit standard deviation within a given region. Column (2) is a Tobit regression that drops Flood $_{t-1}$ from the specification. Column (3) is a Tobit regression that uses a nonparametric bootstrap at the region-year level with 50 replicates to construct standard errors. Column (4) is an OLS regression restricted to region-years such that Slaves $i t>0$ and replaces year fixed effects with region-specific linear time trends. Column (5) is the same as Column (4) but also includes region-specific quadratic time trends. Column (5) is the same as Column (5) but also includes year fixed effects. Robust standard errors are in parentheses below. 
Figure B1: Temperature Voronoi and Regions

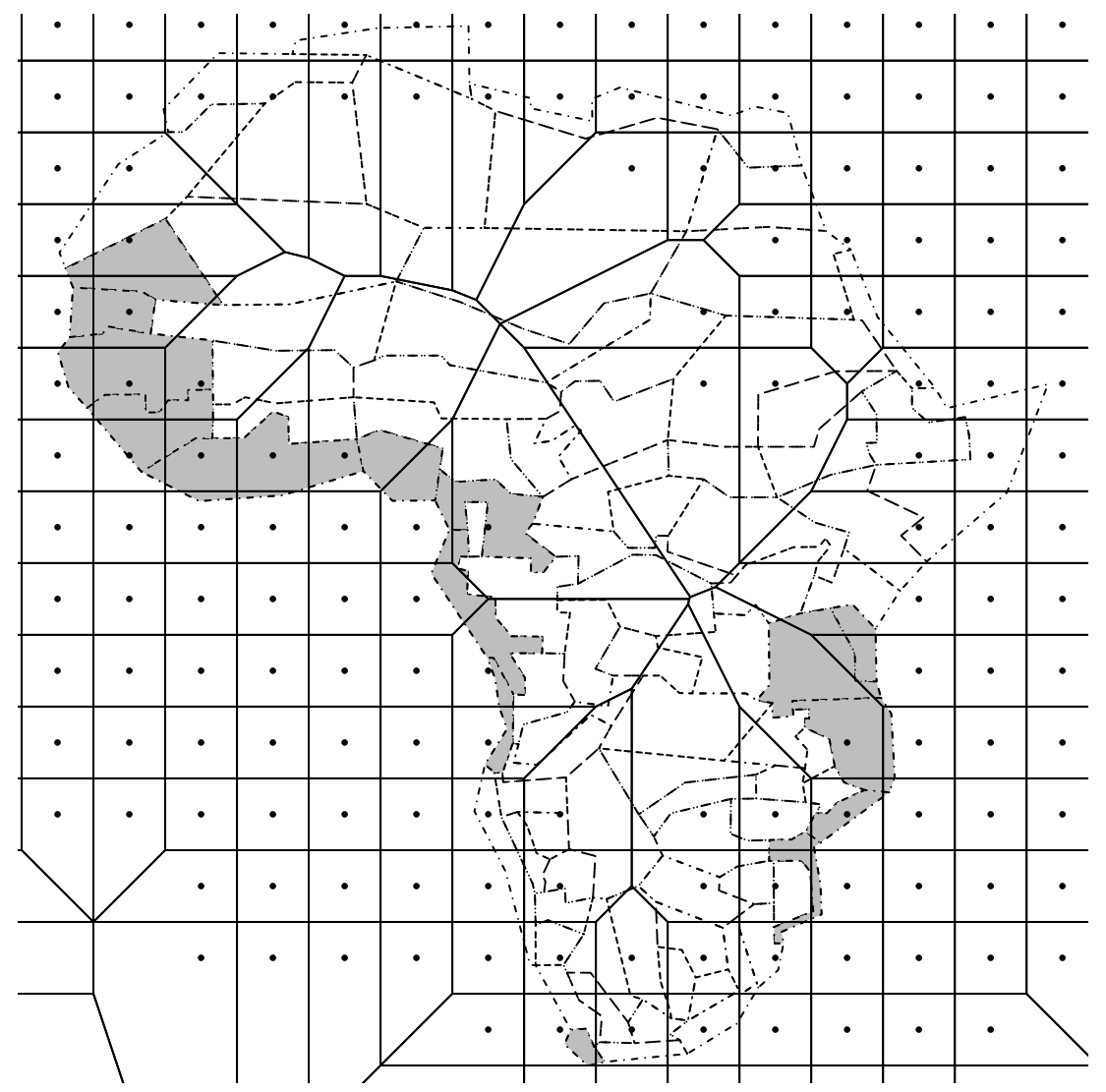

Notes: Data on temperature points comes from Mann, Bradley and Hughes (1998) and rainfall regions (dashed lines) come from Nicholson (2001). Solid lines represent the voronoi polygons from the temperature points that have data throughout the time period. 
Figure B2: Lag Testing — Region Aggregated
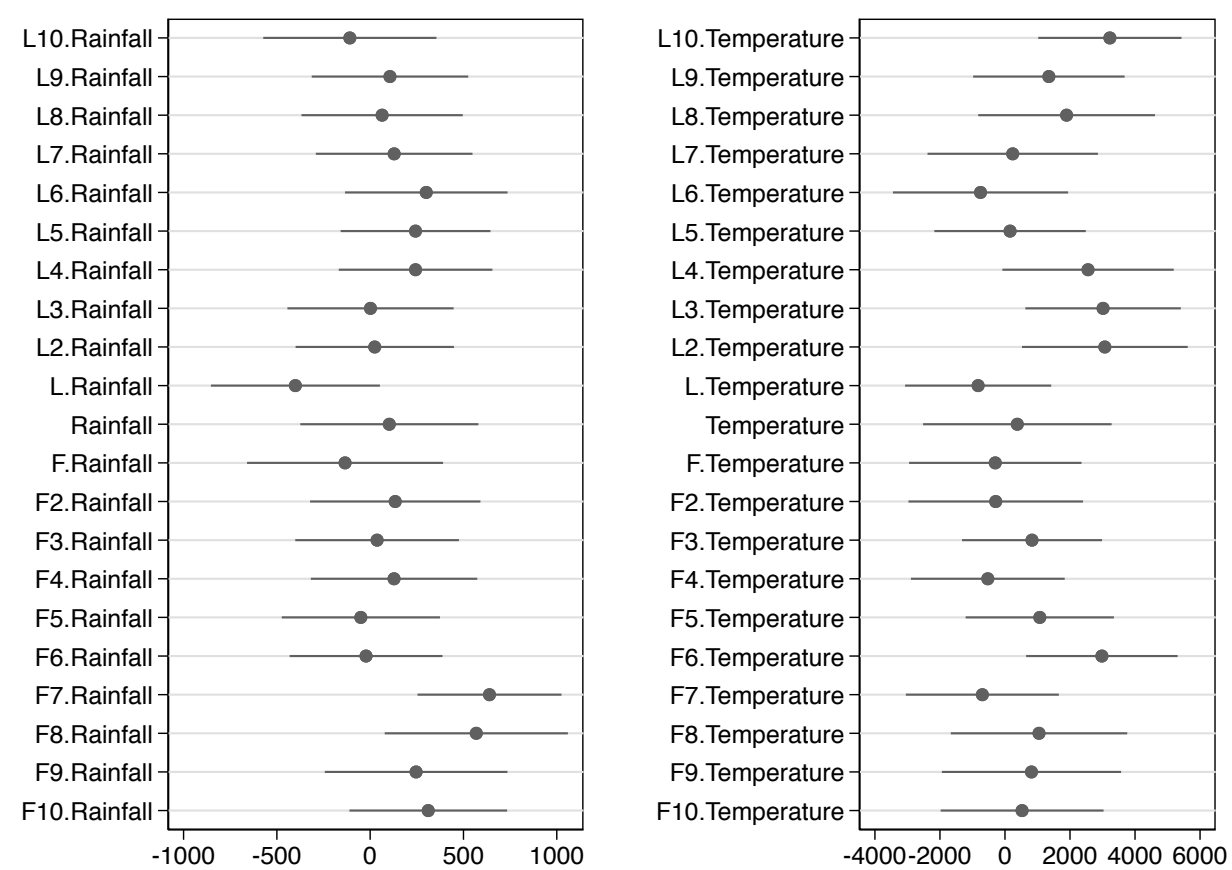

Notes: Figure shows the coefficients along with robust standard errors from two separate Tobit regressions - one with various lagged and future values of rainfall and one with various lagged and future values of temperature. Both regressions use slave exports as their dependent variable and include year and region fixed effects. The rainfall regression also includes the flood indicator variable that corresponds to each rainfall variable. Note that 'L' denotes 'lag' and 'F' denotes 'forward'. 